MICHIGAN RETIREMENT AND DISABILITY RESEARCH CENTER UNIVERSITY OF MICHIGAN

Promoting research on retirement, disability, and Social Security policy

\title{
Interest Rate Trends in a Global Context
}

Dmitriy Stolyarov and Linda L. Tesar

MRDRC WP 2019-402

UM19-05 


\section{Interest Rate Trends in a Global Context}

\section{Dmitriy Stolyarov}

University of Michigan

\author{
Linda L. Tesar \\ University of Michigan
}

\section{September 2019}

Michigan Retirement and Disability Research Center, University of Michigan, P.O. Box 1248. Ann Arbor, Ml 48104, mrdrc.isr.umich.edu, (734) 615-0422

\section{Acknowledgements}

The research reported herein was performed pursuant to a grant from the U.S. Social Security Administration (SSA) funded as part of the Retirement Research Consortium through the University of Michigan Retirement Research Center Award RDR18000002. The opinions and conclusions expressed are solely those of the author(s) and do not represent the opinions or policy of SSA or any agency of the federal government. Neither the United States government nor any agency thereof, nor any of their employees, makes any warranty, express or implied, or assumes any legal liability or responsibility for the accuracy, completeness, or usefulness of the contents of this report. Reference herein to any specific commercial product, process or service by trade name, trademark, manufacturer, or otherwise does not necessarily constitute or imply endorsement, recommendation or favoring by the United States government or any agency thereof.

\section{Regents of the University of Michigan}

Jordan B. Acker; Huntington Woods; Michael J. Behm, Grand Blanc; Mark J. Bernstein, Ann Arbor; Paul W. Brown, Ann Arbor; Shauna Ryder Diggs, Grosse Pointe; Denise llitch, Bingham Farms; Ron Weiser, Ann Arbor; Katherine E. White, Ann Arbor; Mark S. Schlissel, ex officio 


\title{
Interest Rate Trends in a Global Context
}

\begin{abstract}
Long-term interest rates have been falling globally since the early 1980 s and have reached historically low levels. Past forecasts largely missed this secular decline. This paper reviews methodologies for making long-term interest rate projections. We synthesize results from studies that use long historical series and cross-country data to estimate the trend and decompose it into components. We then construct a set of economic indicators that are potentially useful in interest rate forecasting. We add international, forward-looking economic indicators as explanatory variables in a standard macrofinance forecasting model. We find that the model with international variables can outperform the other models by better tracking the falling trajectory of United States interest rates in the post-2008 period, a trend missed by domestic variables. Further, we find that global economic indicators, especially the composite leading indicator for the European Union, are capable of accounting for a large portion of yield variance not only in the U.S. but in other advanced economies as well.
\end{abstract}

\section{Citation}

Stolyarov, Dmitriy, and Linda L. Tesar. 2019. "Interest Rate Trends in a Global Context.” Ann Arbor, MI. University of Michigan Retirement and Disability Research Center (MRDRC) Working Paper; MRDRC WP 2019-402. https://mrdrc.isr.umich.edu/publications/papers/pdf/wp402.pdf 


\section{Introduction}

Social Security Trust Fund projections rely on assumptions about the long-run interest rate. Interest rates are used to discount the benefits stream, to assess fiscal sustainability, and to project income and outlays of the trust funds. It is well known that interest rates have fallen steadily since the early 1980 s in advanced economies, including the United States. Past forecasts largely missed this global, secular decline in interest rates and tended to predict rate reversals toward the long-run historical average year after year.

Yield curves capture rates of return for assets with different maturities. The interest rates' term structures (the return on long- relative to short-run assets) reflects the market response to changing economic conditions in the U.S. and the rest of the world at different horizons. As we show below, some factors move the entire yield curve, while others play a more important role at short relative to long horizons.

This project has two major objectives. First, we review empirical studies on the global component of interest rates and provide a synthesis of methodologies that use cross-country data for U.S. interest rate forecasting. Second, we provide an organizing framework for analyzing influences of domestic and global factors on the dynamics of U.S. interest rates. Ultimately, our analysis will improve our understanding of the factors that drive long-run interest rates and will inform us of the key variables — domestic and foreign — that can be used to forecast rates going forward.

We find that two methodologies are potentially useful for constructing long-range interest rate projections: semi-structural methods of interest rate trend decomposition and standard statistical forecasting models with an extended set of explanatory variables, including forward-looking economic indicators. These methodologies use different data and samples, 
and they provide complementary pieces of information. We deploy both of these methods to examine the determinants of U.S. interest rates.

We perform a decomposition of the long-run nominal interest rate over the period 1981 to 2019 under the restriction of long-run inflation neutrality. Three variables, the earnings-price ratio of the stock market, the weighted average of past and forecasted consumption growth, and year-on-year productivity growth, explain $87 \%$ of variation in the 10 -year real rate. The relative importance of the various macroeconomic determinants changes over time, with the earnings-price ratio mattering most in the 1981 to 1988 period and consumption growth most significant following recessions.

We add international, forward-looking economic indicators as explanatory variables in a standard macrofinance forecasting model. We find that the model with international variables can outperform the other models by better tracking the falling trajectory of U.S. interest rates in the post-2008 period, a trend missed by domestic variables. Further, we find that global economic indicators, especially the composite leading indicator for the European Union, are capable of accounting for a large portion of yield variance not only in the U.S. but in other advanced economies as well.

The paper is organized as follows. Section 2 provides a motivation for the set of macroeconomic variables - domestic and global — that we argue could be incorporated in forecasting models of the interest rate. Section 3 surveys current methodologies for forecasting interest rates and places our approach in the context of the literature. Our analysis of interest rates and their connection to macroeconomic trends is presented in Section 4. Section 5 concludes. 


\section{Drivers of long-run interest rates}

In equilibrium, the real interest rate is jointly determined by the supply of saving and the demand for investment. All else equal, conditions that induce households to set aside more income today and to postpone consumption for later will increase the supply of saving and shift interest rates down. On the other hand, favorable conditions for investment will put upward pressure on interest rates. Governments can affect both the supply of savings and the demand for investment through spending, taxation, and regulatory policies. Finally, as markets become increasingly interconnected, global factors play a role in the determination of U.S. interest rates. In the long-run, monetary policy is to a first-order approximation neutral, so we can abstract from inflation and focus on the long-run "real" determinants of interest rates. We will return to the impact of inflation on the yield curve in Section 4.1.

Table 1 summarizes macroeconomic trends thought to affect long-run interest rates. We discuss each trend in more detail in separate subsections below.

Table 1. Summary of factors affecting long-run interest rates.

\begin{tabular}{|l|c|}
\hline \multicolumn{1}{|c|}{ Macroeconomic trend } & Likely impact on interest rate \\
\hline Falling productivity growth & $\downarrow$ \\
\hline Changing demographics & $\downarrow$ \\
\hline Falling population growth & $\uparrow$ \\
\hline Rising dependency ratio & $\downarrow$ \\
\hline Rising longevity & $\uparrow$ \\
\hline Rising government debt & $\downarrow$ \\
\hline Increased demand for safe assets & $\downarrow$ \\
\hline Financial regulation & $\downarrow$ then $\uparrow ?$ \\
\hline Demand from Pension and Insurance sector & $\downarrow$ then $\uparrow ?$ \\
\hline EME demand for US Treasury securities & $\downarrow$ then $\uparrow ?$ \\
\hline EME demand for foreign exchange reserves & \\
\hline Global imbalances (changing) & \\
\hline
\end{tabular}




\subsection{Labor productivity}

A decrease in labor productivity reduces the capital's marginal product, reduces investment demand, and lowers the interest rate. Labor productivity has been on a secular decline across the largest advanced economies since the 1980s, and this decline coincides with the general decline in long-run interest rates. Views on future long-run productivity range from pessimistic (Gordon 2010) to highly optimistic (Mokyr 2014, Bloom et al. 2014). Our work does not contribute to this debate except to note that historically, the simple link between labor productivity and long-run rates is fairly weak. Figure 1 plots the 10-year U.S. real interest rate and the growth rate of U.S. labor productivity (at the quarterly frequency) over the period 1948 to 2018 , with outlier points and recessions labeled. ${ }^{1}$ The real interest rate is the interest rate on a 10-year Treasury note less the year-on-year inflation rate. Labor productivity is the year-onyear growth rate of labor productivity in the U.S. nonfarm business sector, again at a quarterly frequency. As the figure indicates, there is a significant positive relationship between the two variables, though the coefficient is fairly small (the unconditional regression coefficient of the real rate on productivity growth is 0.23 , with a $p$-value of $\left.1.2 \cdot 10^{-6}\right){ }^{2}$ Our analysis in Section 4 will confirm that productivity is a significant, though somewhat weak, driver of interest rates.

\footnotetext{
${ }^{1}$ Source: Interest rate - Robert Shiller online data. Labor productivity - Bureau of Labor Statistics.

${ }^{2}$ Hansen and Seshadri (2014) consider a longer, 1900 to 2011 sample and find a negative correlation between the real interest rate and productivity growth. This negative correlation appears to be driven by real interest rate volatility early in their sample period that included two wars and the deflation episode associated with the Great Depression. In the 1953 to 2011 subsample of their data, the correlation between productivity and the interest rate is 0.23 , consistent with what we report.
} 
Figure 1. 10-year U.S. real interest rate and the growth rate of U.S. labor productivity.

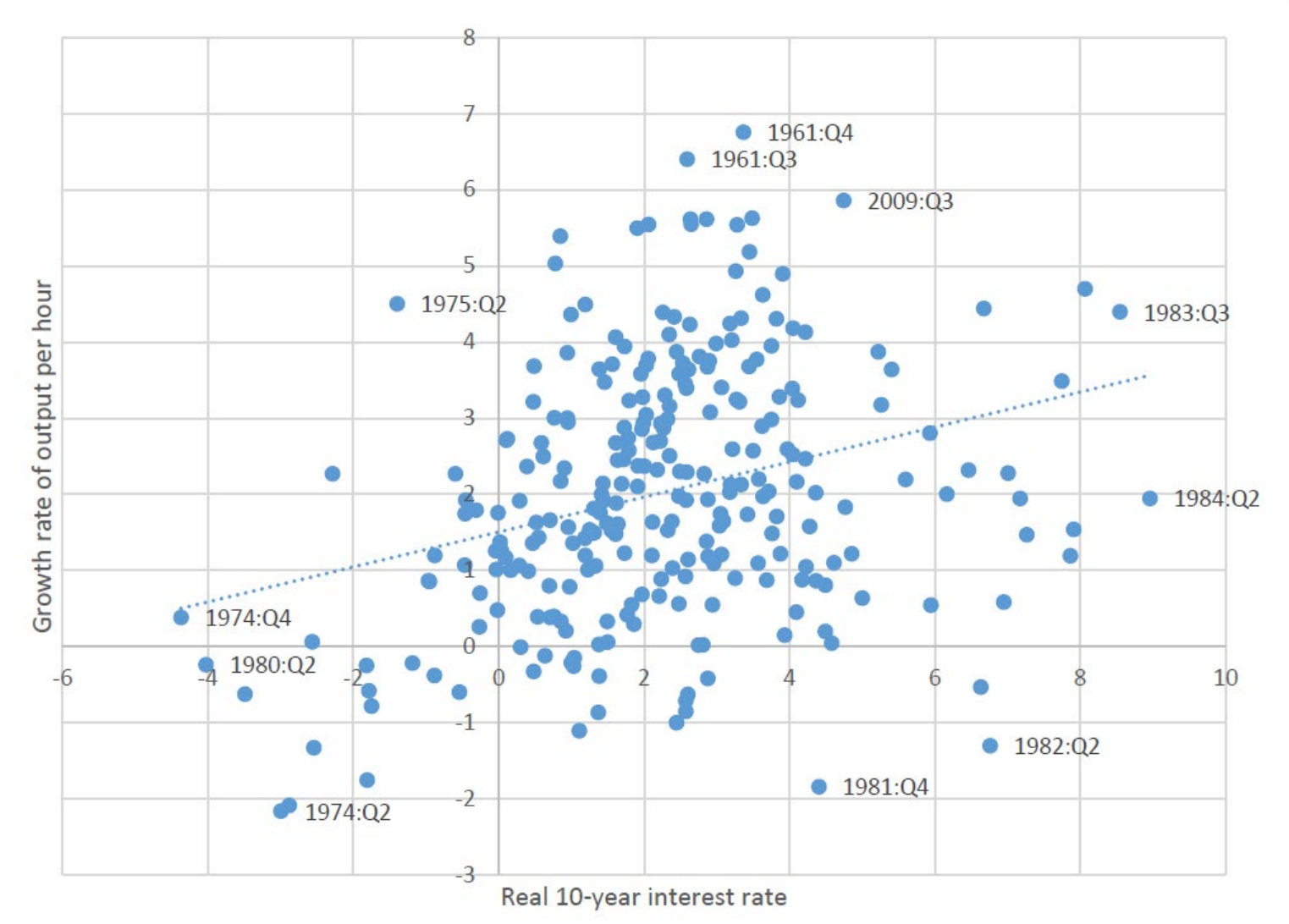

While textbook macroeconomics predicts a positive correlation between the interest rate and productivity growth, a weak or even a negative correlation can be rationalized in a richer macroeconomic model where households' fertility decisions respond to the level of income (e.g. Barro and Becker 1989). We turn next to the role of demographic factors in the determination of interest rates in the medium- to long-run.

\subsection{Changing demographic factors}

The interest rate response to changing demographics is complex because population growth and a changing age structure affect the demand for investment as well as the supply of savings and do so at different horizons. Economic theory predicts that the effect of a permanent decrease in the population growth rate on the long-run interest rate critically 
depends on the extent of familial altruism in household preferences. In the canonical overlapping generations model, for instance, households save only for their own consumption in retirement and leave no bequests. This model predicts that a decline in population growth and a fall in productivity growth are both associated with a fall in the long-run interest rate. By contrast, in the Ramsey model where households take into account the their offspring's wellbeing, population growth changes have a small or even no effect on the long-run interest rate, depending on the extent of familial altruism (e.g. Baker et al. 2005, p. 300).

The term structure of interest rates will reflect both the long-run adjustment to changes in the age composition of the population as well as the transition to the new long-run equilibrium. Life expectancy in advanced economies is projected to rise by about 25 years between 1950 to 2050 , while the population growth rate is expected to fall to virtually zero (see Carvalho et al. 2016, Figure 2). During the transition to an older, longer-lived population, there is downward pressure on interest rates as workers save in anticipation of a longer retirement phase. In the long run, however, the larger share of the elderly in the total population will reduce total private saving and push the interest rate in the opposite direction. Because demographic changes are slow, it is likely that the low rates observed today could persist for some time. However, in the very long run, the rising share of the elderly could begin to push interest rates up. How these changes are reflected in the term structure of interest rates depends on the relative strength of these different effects.

The arguments above focus on the impact of demographic changes on the rate of saving. As Geanakoplos et al. (2004) point out, there is a connection between changes in the population's age composition and the returns to capital as reflected in the earnings-price ratio. This is a relationship that we will explore in section 4.1. Carvalho et al. (2016) argue that the 
demographic transition can affect the equilibrium real interest rate through three channels. An increase in longevity (or expectations thereof) puts downward pressure on the real interest rate, as agents build up their savings in anticipation of a longer retirement period. A reduction in population growth makes the labor force and output grow more slowly, and thereby reduces investment demand. This lowers the rate of return on equity in the business sector. When demand growth is slow, both the earnings-price ratio and the return on equity are lower. We will find below that the earnings-price ratio emerges as a significant driver of long-run interest rates, possibly due to the effects of demographic changes.

\subsection{Government debt}

Government debt ratios as a share of Gross Domestic Product (GDP) rose dramatically in the U.S. and much of Europe after the global financial crisis. Economic theory suggests that, unless Ricardian equivalence holds (i.e., conditions such that households anticipate the higher taxes needed to service the debt and respond by offsetting government dissaving with private saving), increases in government borrowing should result in a downward shift in total savings and an increase in the interest rate. The rise in the interest rate will crowd out private investment and reduce economic activity. Calibrated and estimated dynamic stochastic general equilibrium (DSGE) models tend to predict a crowding out effect from increased government debt, particularly when higher debt is a result of lower growth or increased nonproductive transfers to the private sector.

Despite this theoretical prediction, there is little empirical evidence of a secular trend in long-run rates due to the rise in public sector borrowing or of a crowding out effect on investment. Indeed, in his 2019 Presidential Address to the American Economic Association, Olivier Blanchard argued that in this low interest rate environment that seems set to last, 
increased public debt may come at no fiscal cost and at only a limited cost to overall economic welfare. This is not to say that there is no connection between interest rates and government debt. Concerns about solvency did produce spikes in risk premia for some countries in Europe and there is ample evidence from emerging markets that low economic growth coupled with high public debt can trigger sudden capital flow reversals, high interest rates, and deep economic recessions. Nevertheless, investors generally perceive government debt issued by the largest advanced economies as relatively low risk. Indeed, many have argued that financial sector demand for low-risk, highly liquid assets has played an important role in suppressing interest rates despite high levels of public debt.

Figure 2. Stock of foreign exchange reserves in emerging markets.

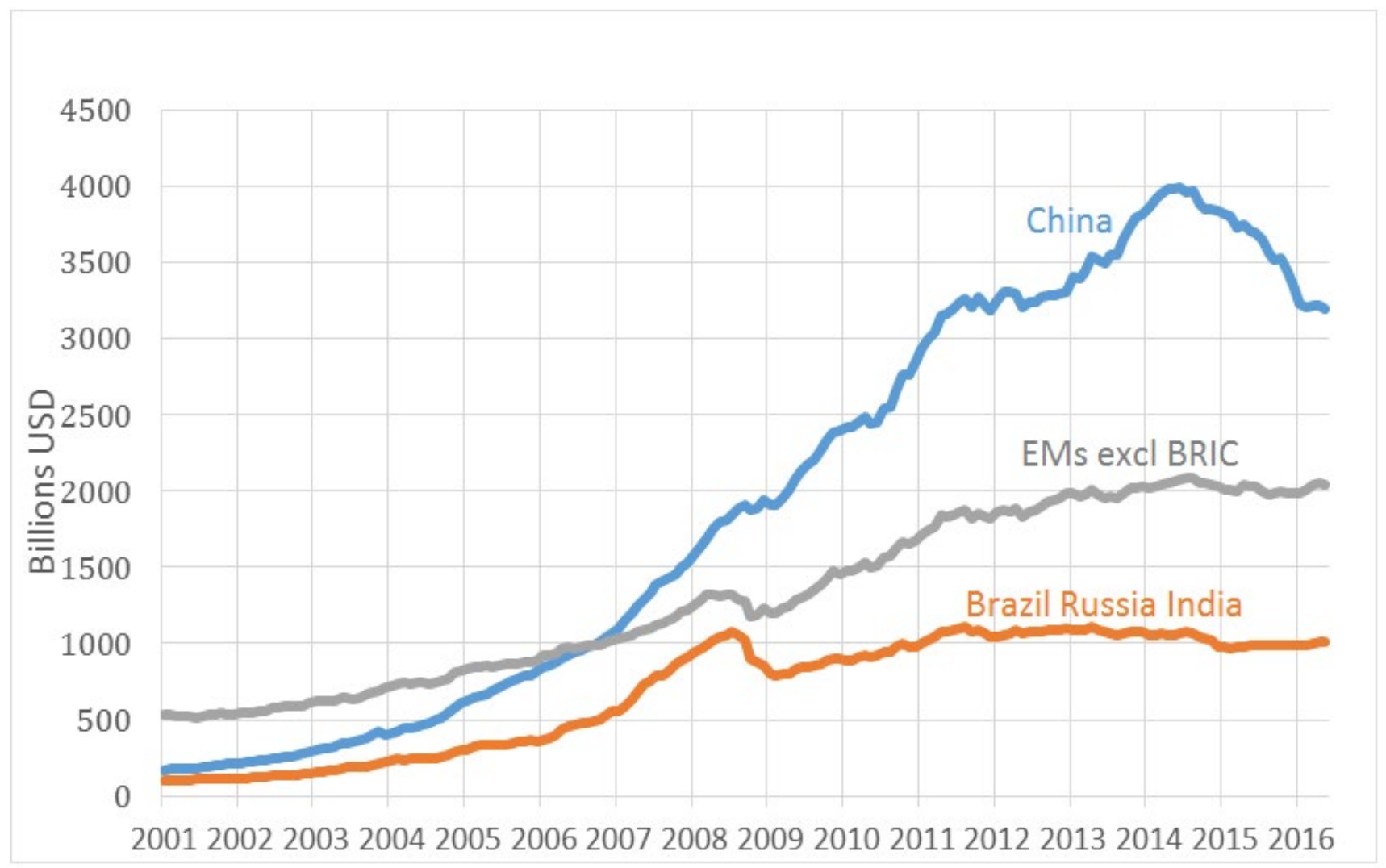

Source: Domanski et al. 2016 


\subsection{Demand for safe assets}

The regulatory response to the financial crisis — chiefly the 2010 Dodd-Frank Act (DFA) — deepened the incentives for holding safe, liquid assets on the part of commercial banks, pensions, and insurance companies. According to Greenwood and Vissing-Jorgensen (2018), the ratio of Treasury holdings to private loans for commercial banks increased five-fold after the DFA and bond prices rose even as the supply of debt expanded. They also document that pension and insurance companies increased their holdings, further driving down yields.

Demand for safe assets is not restricted to U.S. financial institutions. Indeed, by 2017 foreign investors held $\$ 6$ trillion of long-maturity bonds, compared to the $\$ 500$ billion held by U.S. commercial banks. Figure 2 below shows the rise in foreign exchange (FX) reserves held by the emerging markets' (EMEs) central banks, which account for a substantial fraction of foreign holdings of U.S. Treasuries. Domanski et al. (2016) observe that since the global financial crisis, two developments in particular may have increased financial stability concerns in emerging markets and, therefore, a greater need for large, liquid reserves. One is the rapid growth of emerging-market, foreign-currency denominated debt. A second, related trend is growth in emerging-market securities held by foreign institutional investors. Both factors increase the exposure of emerging markets to swings in capital flows and large changes in exchange rates.

It is unclear whether global demand for safe assets will be sustained going forward. As Figure 2 shows, since 2013, major EMEs have on balance sold FX reserves - note especially the sell off by China starting in 2015. If this trend continues, it would exert an upward pressure on U.S. interest rates going forward. 
Figure 3. Saving and investment by country group and for the world economy.

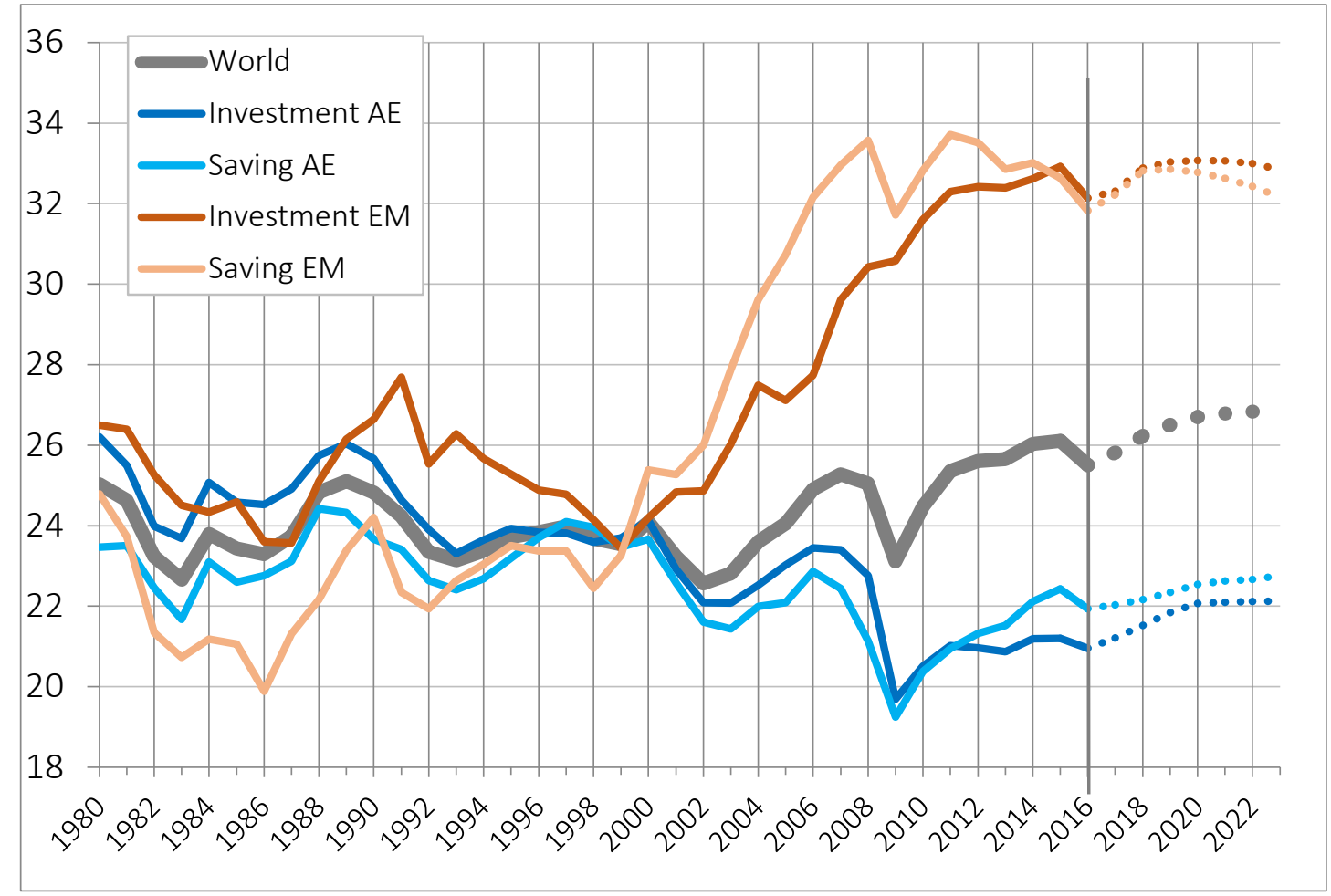

Source: IMF World Economic Outlook, various issues

\subsection{Global saving and investment}

As the discussion on the demand for safe assets implies, global factors are becoming increasingly important for the determination of U.S. interest rates. In a closed economy, the real interest rate is determined by the equality between domestic investment and national saving. In an open economy, a country's savings will seek the global financial market's highest rate of return, and firms wishing to invest will seek out the lowest cost of capital. Ultimately, if markets are fully integrated, the global interest rate will be determined by saving and investment for the world as a whole, with current account balances reflecting the gaps between saving and investment at the national level. 
Figure 3 illustrates saving and investment rates for advanced economies, for emerging markets, and for the world as a whole. The figure reveals the "global imbalances" that emerged during the 2000 s - the rise in emerging market saving relative to investment. Many have argued that the expanded pool of excess savings depressed global interest rates. The consequent search for yield fueled risk-taking behavior in advanced economies, thereby sowing the seeds of the global financial crisis. Leaving the merits of that argument aside, Section 2.4 touched on one explanation for the "excess savings" of emerging markets - the increased demand for dollar reserves as a buffer for potentially disruptive exchange rate movements. Another explanation for the large supply of savings is financial repression in emerging markets. Mendoza, et al. (2009) argue that the combination of limited insurance markets and collateral constraints lead firms to accumulate precautionary savings to selfinsure against adverse shocks. This increased supply of savings suppresses interest rates in emerging markets and helps explain the "excess" supply of savings relative to investment in fast-growing, but high-risk, emerging markets. 
Figure 4. 10-year Treasury rates and historical Blue Chip forecasts

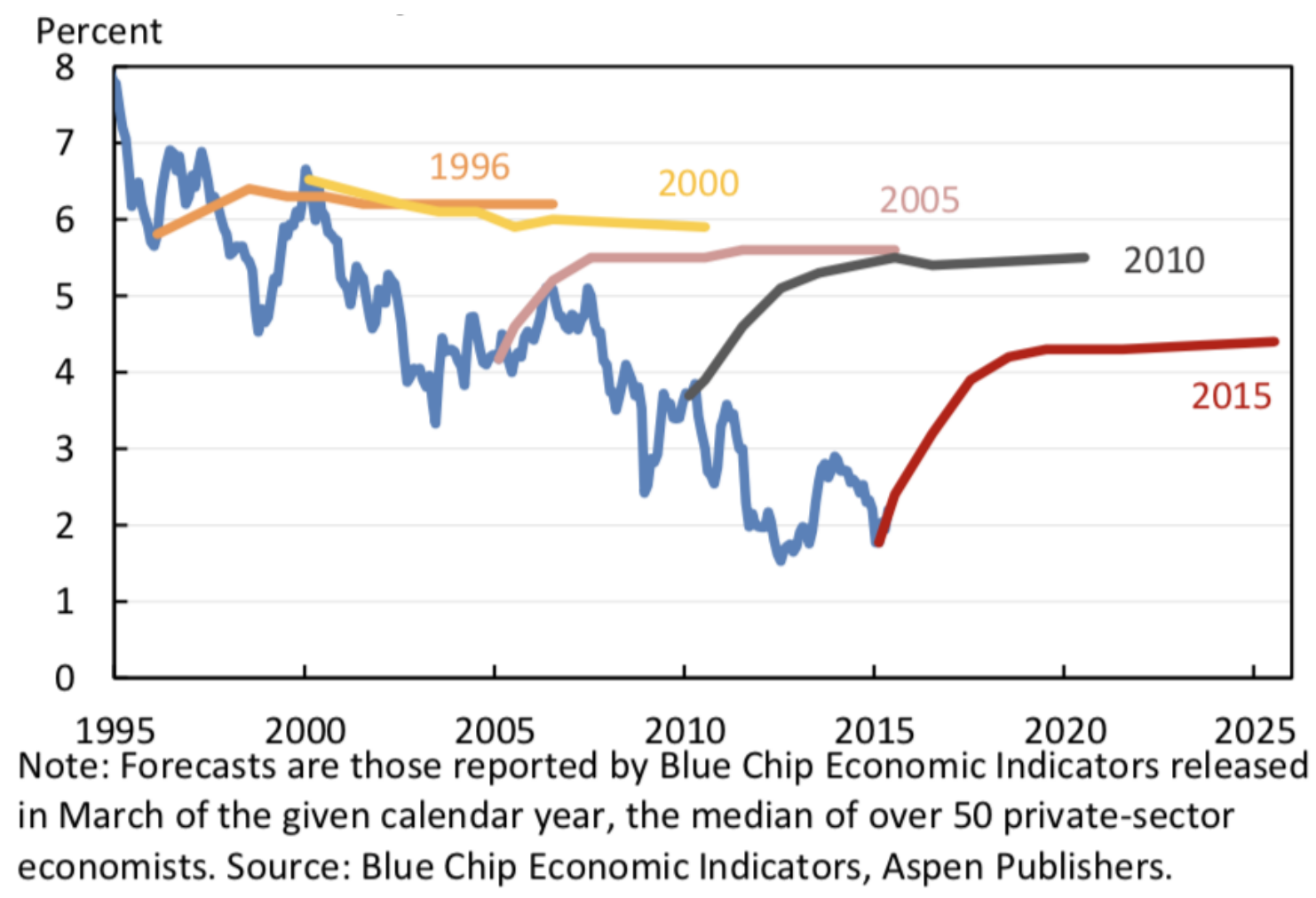

In recent years, evidence of a saving-investment gap between emerging markets and advanced economies has diminished. Indeed, according to International Monetary Fund projections, the gap will be small in the years going forward. As noted above (and shown in Figure 2) China's stock of foreign exchange reserves - a substantial fraction of which is in U.S. Treasuries - has recently reversed course. If these trends continue, the downward pressure on interest rates coming from saving in emerging markets in the future will be lessened.

Summary

An overview of recent trends suggests that changes in demographics, productivity growth, and demand for safe assets by private and institutional investors are important determinants of long-run interest rates. It also is evident that global factors have become more 
important over time. This suggests a possibility that global macroeconomic variables may contain useful information for long-run interest rate forecasts.

\section{Interest rate forecasting methodologies}

Forecasting is hard. For decades, forecasters missed the decline in long-run rates. Figure 4 plots the yield curve forecasts reported by Blue Chip Economic Indicators at different points in time along with the actual path of the U.S. 10-year Treasury rate. As is clear from the figure, while forecasted rates shifted downward somewhat over time, there remained a strong tendency to predict that the long-run rate would revert back to a range of 4 to $6 \%$. This was despite the fact that the 10-year Treasury rate had not consistently remained in that range since the early 2000 s. Eighteen months ago, the 10 -year rate was forecasted to be $3.2 \%$, a full percentage point greater than the actual rate of just below $2 \%$.

\subsection{Econometric models used in yield forecasting}

Forecasting the interest rate is a question of longstanding interest among academics and practitioners alike. For the purposes of this discussion, it is useful to differentiate statistical forecasting models along two dimensions: (i) the set of explanatory variables for bond prices or yields (also referred to as state variables, risk factors, or pricing factors) and (ii) the features of the term structure model, particularly, the inclusion of no-arbitrage conditions.

\subsubsection{Yield curve estimation}

Yield curves are not observed directly, and they must be estimated from a cross-section of bond prices. The estimates are then treated as a data input into an econometric model of the term structure. To explain alternative methods for estimating yield curves, it is helpful to introduce some definitions and notation. Let $P_{n, t}$ denote the date-t price of a zero-coupon bond 
maturing at date $t+n$. The cross-section of bond prices arranged by maturity form a discount curve,

$$
P_{n, t}=e^{-n y_{n, t}},
$$

where $y_{n, t}$ is the zero-coupon yield to maturity. The yields $y_{n, t}$ form the zero-coupon yield curve. At each date $t$, the yield curve reveals the return on the set of bonds with a range of maturities, typically from the "short" end of the yield curve (one to three months) to as long as 30 years. Coupon bonds can be priced in the same way, as the present value of future coupon payments and the principal.

The forward rate, $f_{n, t}$ is defined as the rate of appreciation of a bond as it approaches maturity,

$$
f_{n, t}=-\frac{1}{P_{n, t}} \frac{\partial P_{n, t}}{\partial n}
$$

Accordingly, the yield to maturity is the average of the future forward rates:

$$
y_{n, t}=\frac{1}{n} \int_{0}^{n} f_{\tau, t} d \tau
$$

Two approaches are commonly deployed to estimate the yield curve. The first is to fit a cubic or an exponential spline to the discount curve (e.g., McCulloch 1975, Vasicek and Fong 1982). The second approach is to construct the forward rates sequentially using a maturitysorted bond portfolio (Fama and Bliss 1987), and then to fit a smooth curve to the resulting data on yields.

\subsubsection{State variables}

Researchers use several methods in both the selection and construction of state variables. Most commonly, information contained in the yield curve is summarized by a small set of linear combinations of yields, typically the first three principal components of the 
covariance matrix of yields at different maturities (see Section 4.2 below for details). This reduces the dimensionality of the state vector, an essential step in controlling the number of parameters to estimate.

While the principal component approach is the most common, the dynamic NelsonSiegel model uses a somewhat different method for summarizing the yield curve. The model fits a functional form for the yield curve to the cross-sections of yields to estimate the latent state variables. One advantage of this method is that latent variables thus constructed have a clearer interpretation as level, slope, and curvature factors, whereas the same interpretation for principal components holds in a less precise sense.

Statistical models of the term structure fall into two categories with respect to the set of the state variables they use. Yields-only models use only the information contained in yield curves themselves. Macrofinance models add other observables, such as measures of real activity, inflation, and information from macroeconomic forecasts. We discuss the macrofinance models in more detail in Section 3.1.4.

Table 2. Categories of statistical models for interest rate forecasting.

\begin{tabular}{|c|c|c|c|}
\hline \multirow[b]{2}{*}{ Model type } & \multicolumn{3}{|l|}{ State variables } \\
\hline & $\begin{array}{l}\text { Latent variables } \\
\text { deriving from yields }\end{array}$ & $\begin{array}{l}\text { Latent and } \\
\text { macroeconomic } \\
\text { variables }\end{array}$ & $\begin{array}{l}\text { Latent, } \\
\text { demographic and } \\
\text { macroeconomic } \\
\text { variables }\end{array}$ \\
\hline $\begin{array}{l}\text { No-arbitrage affine } \\
\text { model }\end{array}$ & Adrian et al. 2013 & $\begin{array}{l}\text { Ang and Piazzesi 2003; } \\
\text { Wright } 2011\end{array}$ & \\
\hline $\begin{array}{l}\text { Reduced form affine } \\
\text { model }\end{array}$ & Abbritti et al. 2018 & $\begin{array}{l}\text { Ludvigson and } \mathrm{Ng} 2009 ; \\
\text { Joslin et al. 2014; } \\
\text { This paper }\end{array}$ & Favero et al. 2016 \\
\hline $\begin{array}{l}\text { Reduced form } \\
\text { dynamic Nelson- } \\
\text { Siegel model } \\
\end{array}$ & $\begin{array}{l}\text { Diebold and Li 2006; } \\
\text { Diebold et al. } 2008\end{array}$ & Coroneo et al. 2014 & \\
\hline
\end{tabular}


Table 2 presents a taxonomy of statistical models commonly used in interest rate forecasting. Besides using different sets of state variables, common models in the literature differ with respect to imposing no-arbitrage conditions on the time series of bond prices. Reduced form models require that bonds be consistently priced in a cross-section. Noarbitrage models require, in addition, that bonds be consistently priced over time. In the next subsection, we discuss no-arbitrage conditions in more detail.

\subsubsection{No-arbitrage conditions}

Forecasting methods grounded in finance theory start with the premise that asset prices incorporate all information available to investors and that arbitrage opportunities are either absent or transitory. The information available to investors at date $t$ is contained in the state vector $X_{t}$. The state vector follows a Markov process that captures the evolving set of information relevant for computing conditional expectations of future interest rates and bond prices. The model specifies an intertemporal, no-arbitrage condition of the form

$$
P_{n, t}=\mathbb{E}_{t}\left(M_{t+1} P_{n-1, t+1} \mid X_{t}\right)
$$

where $P_{n, t}$ is the price of a bond with maturity $n$ at date $t$ and $M$ is the stochastic discount factor, also referred to as the pricing kernel. Estimating the model involves estimating the stochastic process for the state vector as well as the functional form for the stochastic discount factor, $M\left(X_{t}\right)$. A widely used class of empirical no-arbitrage models used to obtain joint forecasts of future yields, future returns, and risk premia derive from the class of affine yieldfactor term structure models is introduced in Duffie and Kan (1996) and categorized in Dai and Singleton (2000). 
One advantage of no-arbitrage models is that they can interpret information contained in a panel of bond prices rather than working off repeated cross-sections. Another advantage is that a no-arbitrage model can separately quantify the effects of individual risk factors on bond prices by estimating a functional form for the stochastic discount factor. This is useful, in particular, for pricing derivative securities. The main disadvantage of no-arbitrage models is that their estimation is usually computationally intensive, and computational constraints may limit the size of the state vector for which estimation is practical. ${ }^{3}$

Reduced-form affine models posit a linear relationship between yields and pricing factors, but they do not impose intertemporal no-arbitrage conditions requiring that bonds be priced consistently at different dates. No-arbitrage conditions do not affect the dynamics of the state variables, but they do affect the mapping from state variables to yields.

In general, it is not clear whether reduced-form and no-arbitrage models produce significantly different interest rate forecasts despite the different specification of the mappings from states to yields. Pericoli and Taboga (2012), for example, show that the fitted yields almost coincide between a no-arbitrage affine term structure model and its reduced-form counterpart. In contrast, Ang and Piazzesi (2003) show that the model with no-arbitrage conditions forecasts better than one without.

In some cases, it is possible to theoretically show that omitting no-arbitrage conditions involves no loss of information. For instance, Joslin et al. (2011) provide conditions when the

\footnotetext{
${ }^{3}$ Adrian et al. (2013) estimate the affine term structure model without imposing cross-parameter bond pricing restrictions derived from no-arbitrage conditions. They instead incorporate a return pricing error into equation (3). The resulting system of equations can be estimated with a multistep linear procedure. Their procedure does not rely on a constructed yield curve, as it can use coupon bond prices directly as a data input.
} 
no-arbitrage restrictions have no effect on the maximum likelihood parameter estimates within a class of yields-only affine models.

The approach we take in this paper is to use a reduced-form affine model. This is partly because our focus is interest rate forecasting rather than asset pricing. The advantage is that the model can be consistently estimated with simple OLS, and we thus avoid computational complexities stemming from a nonlinear estimation procedure.

\subsubsection{Macrofinance models}

The role of macroeconomic factors in interest rate forecasting in addition to yield-only factors is a subject of ongoing investigation and debate. To frame our discussion, it is convenient to use a decomposition of bond yields into a sequence of expected short rates and expected excess returns. One can show that (see, e.g., Duffee 2013) the current yield on an $n$ period bond equals the sum of expected future short rates and the risk (or term) premium that depends on expected future excess returns:

$$
y_{n, t}=\frac{1}{n} \sum_{\tau=1}^{n-1}\left[\mathbb{E}_{t}\left(y_{1, t+\tau} \mid X_{t}\right)+\mathbb{E}_{t}\left(r x_{t+\tau-1, t+\tau}^{n-\tau} \mid X_{t}\right)\right],
$$

where the excess return is defined as

$$
r x_{t, t+1}^{n}=\ln \left(\frac{P_{n-1, t+1}}{P_{n, t}}\right)-\ln \left(\frac{1}{P_{1, t}}\right) .
$$

The yield decomposition in Equation (2) is helpful for understanding the role of information contained in the state variables. In particular, Equation (2) illustrates an interesting possibility that there can be so-called "hidden factors" — state variables that have opposite and offsetting effects on expected short rates and expected excess returns (see, e.g., Duffee 
2011 and Joslin et al. 2014). Such factors can have a small effect on the cross section of yields but potentially large effects on the dynamics of yields themselves. For this reason, if hidden factors are present, the information contained in the current cross-section of yields is insufficient for forecasting future yields. Macroeconomic variables seem to be natural candidates as potential hidden factors since economic theory predicts a relationship between real activity and future yields.

Accordingly, a large body of recent research focuses on incorporating macroeconomic variables in econometric frameworks for yield forecasting. It is unclear which set of macroeconomic variables is a good candidate for hidden factors. Our analysis in Section 4.3 adds to this aspect of the macrofinance body of research by expanding the set of macroeconomic variables to include not just domestic economic indicators and forecasts, but also measures of global real activity.

One advantage of macrofinance models is that they link the dynamics of macroeconomic variables to the dynamics of yields. This potentially allows using economic theory to inform the selection of the econometric model's state variables, incorporating macroeconomic forecasts in the estimation, and quantifying the relationships between yields and macroeconomic fundamentals.

Potential parameter instability is another reason to include macrovariables in forecasting models. If the relation between macrovariables and expected yields is believed to be more stable over time than the one between current yields and expected yields, forecasts based on macroeconomic variables may turn out to be more reliable. However, with sample lengths of 150 quarters or so, even macrofinance models may fail to capture low-frequency movements in yields, and they may incorrectly attribute observed trends to a sequence of random shocks. 
Economic theory predicts that macroeconomic variables may help forecast the level component of yields in particular. Prior research on yields-only models has cast doubt on whether the current term structure contains information about changes in the future level of yields (e.g., Duffee 2011, Table 2). Accordingly, yields-only models may not be as informative on predicting the change in yield levels.

An extension of the macrofinance model uses additional insights from economic theory that suggests population composition can account for low-frequency movements of interest rates. ${ }^{4}$ Favero et al. (2016) add the population composition state variable (specifically, the $M Y$ ratio that we depict on Figure 5) to an otherwise standard reduced-form term structure model. Besides latent factors and population composition, the model's state vector includes inflation and output gap. Their estimates find a significant effect of the population composition trend itself an echo effect of the baby boom — on the level component of yields. This result suggests that population composition changes may have contributed to falling interest rates in the 1980s and 1990s. Most recently, however, the demographic and the interest rate trends have diverged: the $M Y$ ratio has bottomed out in 2003 and has been growing for the past 15 years whereas the real rates kept falling. If anything, the current population composition should put upward pressure on the interest rate most recently. ${ }^{5}$

\footnotetext{
${ }^{4}$ Geanakoplos et al. (2004) argue that demographic changes in the U.S. induced cyclical behavior of security prices. They use an overlapping generations model with a time-varying demographic structure to show that the rates of return on equity and bonds rise with the change in the ratio of middle-aged to young agents. This is driven by life-cycle saving behavior. For instance, a large middle-aged cohort seeking to save for retirement will push up the prices of financial assets (see also Section 4.1 below).

${ }^{5}$ Del Negro et al. (2018, Figure 5), show that this phenomenon is not specific to the U.S: $M Y$ ratios are trending up in Germany, U.K., and Canada while their real rates are falling.
} 
It is still unclear whether macrofinance models improve forecasting the level component of the yield curve. Ang and Piazzessi (2003), for instance, obtain virtually the same dynamics of the level factor whether or not macroeconomic variables are included. This suggests that macroeconomic variables add little to the model's ability to predict the changes in the level of yields. Our results in section 4.4 are somewhat more nuanced. We estimate a dynamic model of yields to check whether forward-looking economic indicators - U.S. as well as global appear to be hidden factors.

Our estimates of the model with macrovariables show that the level component of yields depends on both productivity growth and expected inflation, and the component's estimated persistence is substantially reduced compared to that in the yields-only model. This finding contrasts with Ang and Piazzesi (2003), however, it appears to be sensitive to both the sample period and the set of macroeconomic indicators included in the model.

Overall, the literature on macrofinance forecasting models seems to suggest that real activity indicators are useful in understanding risk premia on bonds. There is less evidence on whether forecasting models can predict changes in interest rate levels, although this paper's results offer some hope in this respect.

The above discussion outlines difficulties in using forecasting models for predicting interest rate trends. Accordingly, the question of constructing long-run interest rate projections calls for a broader set of methodologies, including those that use insights from economic theory to inform empirical specifications. We next turn to reviewing analyses that specifically focus on interest rate trends. 


\subsection{Interest rate trend decompositions}

This section reviews several methodologies for long-run interest rate projections and outlines some conclusions that can be drawn from them. These approaches use semistructural methods to understand long-run interest rate trends from asset pricing and wealth accumulation perspectives.

\subsubsection{Interest rate trend estimation and decomposition using cross-country data}

In Section 3.1, we made an argument for using long historical samples for the purposes of detecting interest rate trends. One example of this approach is undertaken in a paper by Del Negro et al. (2018). They jointly estimate trends in real rates for seven advanced economies using data on short- and long-term interest rates, inflation, and consumption starting in 1870. The method decomposes real rates and term premia into a common component, a countryspecific component, and a convenience yield, which is a rate cut that investors are willing to take in exchange for holding a safe and liquid asset. Convenience yields are identified with the assumption that all assets are priced with the same stochastic discount factor. The stochastic discount factor is tied to data on consumption growth.

The analysis points to three major drivers of falling interest rates since the 1980s: increasing convenience yield, a slowdown in global growth, and an increase in desired saving. The rising convenience yield accounts for more than half of the world real interest rate decline (more than 90 basis over the past 25 years), and it makes a larger contribution to the declining rate since 1997. The slowdown in global growth accounts for about one-third of the decline, or 60 basis points. The rest of the decline, about 40 basis points, is attributed to a rising desire to save. 
The account of rising convenience yield and rising desire to save as drivers of the lower world interest rate appears to be consistent with "safe asset shortage" as an explanation for low rates (e.g., Caballero et al. 2017). According to this view, the rise in the emerging economies' wealth may have changed the composition of international investors in terms of their risk attitudes and the overall desire to save, and this change brought about rising convenience yields and falling rates. ${ }^{6}$

Factors other than capital flows from emerging markets might have contributed to rising convenience yields over the same period. Pension and insurance (P\&I) companies in developed economies are large buyers of long-maturity bonds, for reasons having to do with both regulation and liability-matching. Changes in regulation of P\&I companies have been shown to make a significant impact on interest rates. ${ }^{7}$

Convenience yields cannot expand indefinitely. In fact, if a large portion of demand for safe assets comes from emerging economies, the global economic growth slowdown may reduce capital flows into safe assets, as discussed in Sections 2.4 and 2.5. The perceived safety of government debt itself depends on its growth relative to a country's repayment capacity. The recent changes in capital flows shown on Figures 2 and 3, as well as recent rapid growth of debt-GDP ratio in the U.S. may temper or reverse the rise in convenience yield.

More generally, changes in wealth accumulation patterns on a global scale may encode information about the trajectory of future interest rates. In the next section, we look at the

\footnotetext{
${ }^{6}$ Caballero et al. (2008) and Hall (2016) propose stylized theoretical frameworks tailored to illustrating the impact of risks faced by emerging economies on the interest rate trends.

${ }^{7}$ Greenwood and Vissing-Jorgensen (2018) show that regulation-induced changes in demand for longterm bonds can cause large movements in the slope at the long end of the yield curve. Their findings suggest that the difference between P\&I asset to GDP ratio and government debt to GDP ratio has a correlation of about -0.7 with the 30 -year to 10 -year yield spread.
} 
present value method aimed at extracting this information from the time path of the consumption-wealth ratio.

\subsubsection{Present value approach}

Gourinchas and Rey (2019) is another example of a methodology that uses both a long historical sample and a global perspective to understand interest rate trends. They use a present-value global resource constraint to link the past dynamics of consumption to wealth ratio and the future interest rate trajectory. A high consumption to wealth ratio is proposed as an indicator of future low rates.

With the present value approach, growth in consumption-wealth ratio can be decomposed into expected change in the risk-free interest rate, expected change in the risk premium, and expected change in consumption growth rate. If changes in risk premium or consumption growth rate are not forecastable, a high consumption-to-wealth ratio would indicate that the interest rate is on a falling trajectory. Consistent with this intuitive description, Gourinchas and Rey (2019) show that consumption-to-wealth ratio does predict risk-free rates.

The main results in Gourinchas and Rey (2019) are broadly consistent with those in Del Negro et al. (2018). Gourinchas and Rey (2019) find that productivity growth and population growth partially account for the downward trend in the risk-free rate. They also show that a rise in desire to save and reduced appetite for risk are major contributors to the falling interest rate trend. However, they interpret the changes in investor behavior as stemming from deleveraging after the great financial crisis. Deleveraging might provide an alternative interpretation for recently growing convenience yields measured in Del Negro et al. (2018).

Long-range forecasts in Gourinchas and Rey (2019) suggest that an extended period of low interest rates is ahead, with the U.S. annual real risk-free rate of $-1.3 \%$. In large part, their 
proposed explanation for the low interest rate is increased demand for saving stemming from the protracted deleveraging process that followed the Great financial crisis.

\section{Summary}

Studies mentioned above suggest that a global perspective on interest rates can deliver useful insights by extracting information from a richer body of evidence interpreted through the lens of economic theory. Moreover, semistructural methods inform long-range interest rate projections in ways that complement statistical forecasts. For instance, a quantitative interest trend decomposition into contributing factors opens a possibility for scenario forecasting based on assumptions about persistence or reversal of separate factors related to risk preferences, saving behavior, or global macroeconomic conditions.

Interest rate trend decompositions also inform on the selection of state variables for a macrofinance forecasting model. If changes in risk attitudes are an important driver of interest rates, forward-looking indicators - such as measures of consumer and business confidence — may contain valuable information for statistical forecasting.

In the next section, we use insights from interest rate trend decompositions to add forward-looking economic indicators to the state variable set of a standard macrofinance forecasting model. We experiment with both domestic and global forward-looking indicators and assess the model's ability to forecast the level component of yields.

\section{Economic indicators potentially useful in interest rate forecasting}

One of our goals is to identify a set of economic indicators that capture the dynamics of interest rate trends. These indicators may also prove to be useful for forecasting. We start with 
an analysis of the 10-year U.S. Treasury rate to understand interest rate dynamics since 1981, the point at which nominal rates in the U.S. and foreign markets began their decline.

\subsection{0-year Treasury rate decomposition}

We rely on economic theory to guide our choice of variables to include in the analysis, although we do not take a firm stand on the precise specification of a model. We use quarterly data from 1981:Q3 to 2019:Q1. The dependent variable to be explained is the 10-year nominal Treasury rate. $y_{10, t}$.

Up to this point, our discussion has focused on the determinants of the long-run real interest rate. The variable we observe, however, is the long-run nominal interest rate. While most economists would agree that the role of inflation is likely to be small if not zero in the very long run, inflation will affect yields at shorter maturities as we will show below. We, therefore, include inflation as a control. Because expectations about future inflation are important for the current interest rate, we include a time-smoothed measure of inflation that includes expected inflation as well as past inflation. Our measure is:

$$
\pi_{t}=\omega \pi_{t-4}+(1-\omega) \pi_{t+4}^{e}
$$

where $\pi_{t-4}$ is CPI inflation rate over the past four quarters and $\pi_{t+4}^{e}$ is expected inflation over the next 4 quarters. ${ }^{8}$

The second explanatory variable included in our analysis is the growth rate of consumption. Macroeconomic theory interprets the "stochastic discount factor" $M$ in section 3.1.3 as the expected intertemporal marginal rate of substitution in consumption. We,

${ }^{8}$ Data sources: $\pi_{t-4}, g_{C, t-4}-$ NIPA CPI inflation and growth rate or private consumption expenditure, $\pi_{t+4}^{e}, g_{C, t+4}^{e}$ - Survey of Professional Forecasters. 
therefore, include the growth rate of real private consumption expenditure (PCE), which is again smoothed over time to include both past and future expected consumption growth:

$$
g_{C, t}=\frac{1}{2} g_{C, t-4}+\frac{1}{2} g_{C, t+4}^{e}
$$

where $g_{C, t-4}$ is the growth rate of the real private consumption expenditure over the past four quarters and, and $g_{C, t+4}^{e}$ is the forecast of the same, four quarters forward. Note that because we are using total real PCE and not per capita PCE, changes in population growth will also be picked up by this variable.

We also include a measure of labor productivity growth, $g_{y, t-4}$, measured as the growth rate of business sector real output per hour over the previous four quarters. Although we saw in Figure 1 that there is only a weak, unconditional relationship between productivity growth and the long-run rate, we include it in the analysis because it is possible that productivity growth will play a stronger role after conditioning on other variables.

Finally, we include in the regression the inverse of Robert Shiller's CAPE ratio - that is, the ratio of average real earnings 10 years back to the current inflation-adjusted S\&P index as our financial market variable, denoted $E P_{t}$. In the textbook macroeconomic model, the longrun value of this ratio is equal to the real rate of equity return in the business sector. If equity returns are high, this could be a signal that the returns to investment are high and interest rates will also be high.

Another reason for inclusion of the CAPE ratio is that, as we noted above, cyclical variations in $E P_{t}$ seem to capture the effects of population dynamics on asset returns (Geanakoplos et al. 2004). In particular, Geanakoplos et al. (2004) suggests that the relevant demographic variable is the ratio of young workers (ages 20 to 29) to workers in the middle of the age distribution (ages 40 to 49), denoted the by YM ratio. Figure 5 depicts the relation 
between Shiller's $E P$, the real 10-year rate, and the YM ratio since 1953. The YM ratio, EP, and real rate all track one another well since the 1960s. However, the YM ratio bottomed out in 2002 and has been rising since. If anything, the demographic argument suggests that the changing age composition of the population should be putting an upward pressure on the real rate and on EP. Del Negro et al. (2018) point out the divergence between YM and interest rates for other countries as well.

Figure 5. Earnings-to-price ratio, 10-year real rate, and young-to-middle (20 to 29 year olds over 40 to 49 year olds) ratio.

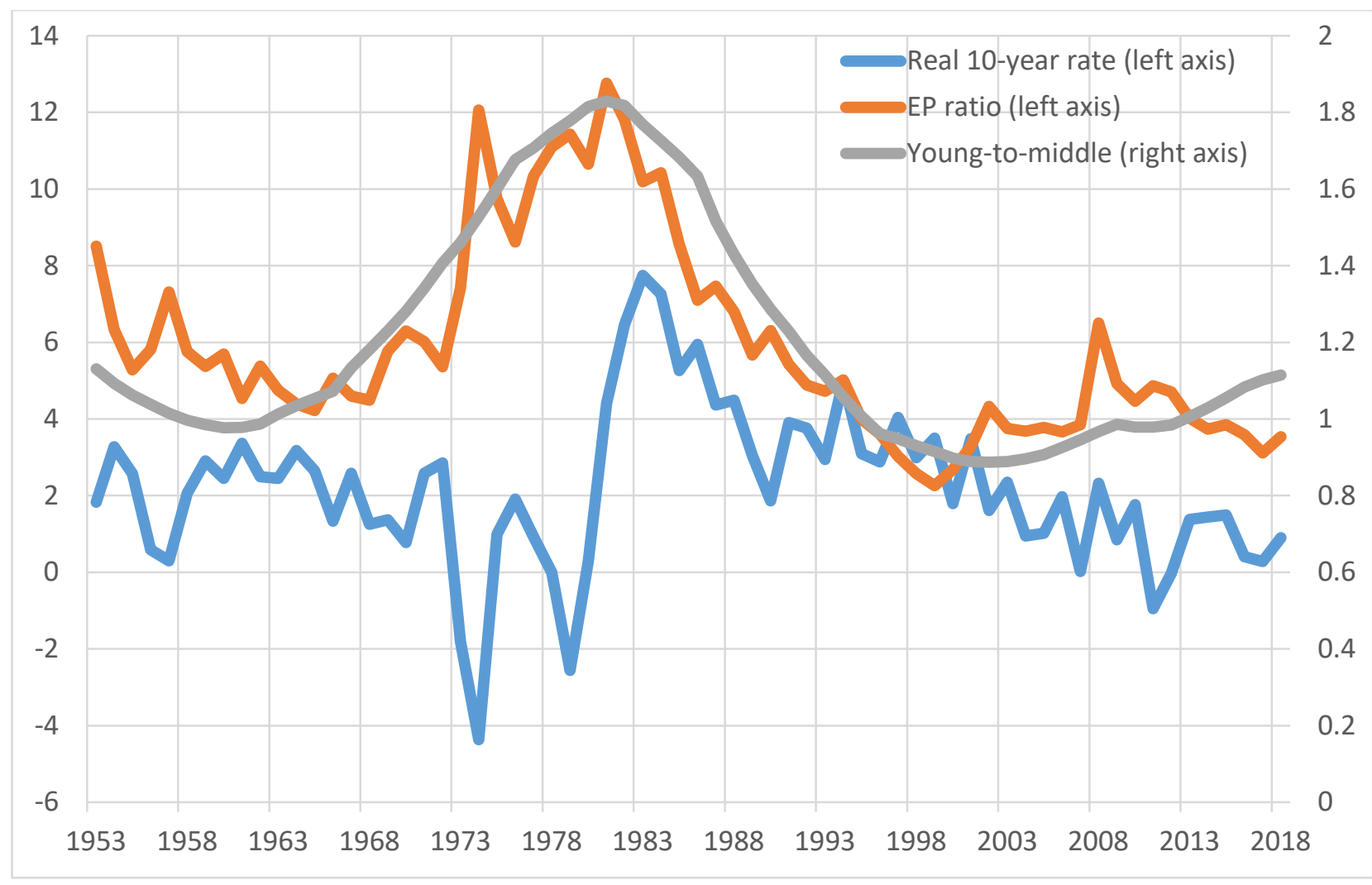

The estimating equation is

$$
y_{10, t}=\beta_{0}+\beta_{\pi} \pi_{t}+\beta_{C} g_{C, t}+\beta_{y} g_{y, t-4}+\beta_{E P} E P_{t} .
$$


We take the stand that, in the long run, inflation is neutral, so that a 1 percentage point increase in inflation that is expected to be permanent should lead to a 1 percentage point rise in the long-run nominal rate. Accordingly, we choose the weight $\omega$ so that the coefficient $\beta_{\pi}=$ 1. Under this restriction, Table 3 reports the estimates for the coefficients on consumption growth, productivity growth, and the EP ratio (the units of interest rates and growth rates are annual percent).

Table 3. 10-year rate decomposition.

\begin{tabular}{|l|c|c|c|c|c|}
\hline 10-year rate & $\boldsymbol{\beta}_{\boldsymbol{\pi}}(\boldsymbol{\omega}=\mathbf{0 . 6})$ & $\boldsymbol{\beta}_{\boldsymbol{C}}$ & $\boldsymbol{\beta}_{\boldsymbol{y}}$ & $\boldsymbol{\beta}_{\boldsymbol{E} P}$ & $\boldsymbol{\beta}_{\mathbf{0}}$ \\
\hline Coeff. & 1.00 & 0.74 & 0.34 & 0.64 & -2.28 \\
\hline Std. error & 0.12 & 0.09 & 0.07 & 0.06 & 0.35 \\
\hline \multicolumn{2}{|r|}{$\boldsymbol{R}^{\mathbf{2}=\mathbf{0 . 8 7}}$} & $N=151$ & \multicolumn{4}{l}{} \\
\hline
\end{tabular}

The regression coefficients in Table 3 can be interpreted as the elasticities of the nominal 10-year rate with respect to the rate of inflation, growth rate of private consumption expenditure, productivity growth, and the earnings-to-price ratio. Each of the variables enters with the expected sign, with increases in productivity growth, consumption growth, and the EP ratio all contributing to an increase in the interest rate. The largest elasticities as estimated over the full sample are with respect to private consumption growth and the EP ratio.

Figure 6 below illustrates the changing contribution of each factor over time. The solid blue line is the predicted real rate, $y_{10, t}-\beta_{\pi} \pi_{t}$. We net out the impact of inflation, so that we can focus on the drivers of the long-run real interest rate. In the 1980s, the real interest rate (the dark blue line) and the contribution of the EP ratio $\left(\beta_{E P} E P_{t}-\beta_{0}\right.$, the orange shaded area) were both high. Recall from Figure 5 that the young-to-middle ratio was high in that period, consistent with a high ratio of dis-savers in the economy and, therefore, a high interest rate. This demographic factor falls off by 1988 , and coincides with the drop in the real rate over the 
1980s. The contribution of productivity growth ( $\beta_{y} g_{y, t-4}$ in grey) to the real interest rate is small throughout the sample. The figure illustrates the collapse and then recovery of consumption $\left(\beta_{C} g_{C, t}\right.$ in yellow) in each of the recessions, accompanied by a fall and then an increase in the interest rate. By the end of the sample, the real interest is lower than what is predicted given the rate of consumption and productivity growth.

\section{Figure 6. Real interest rate decomposition}

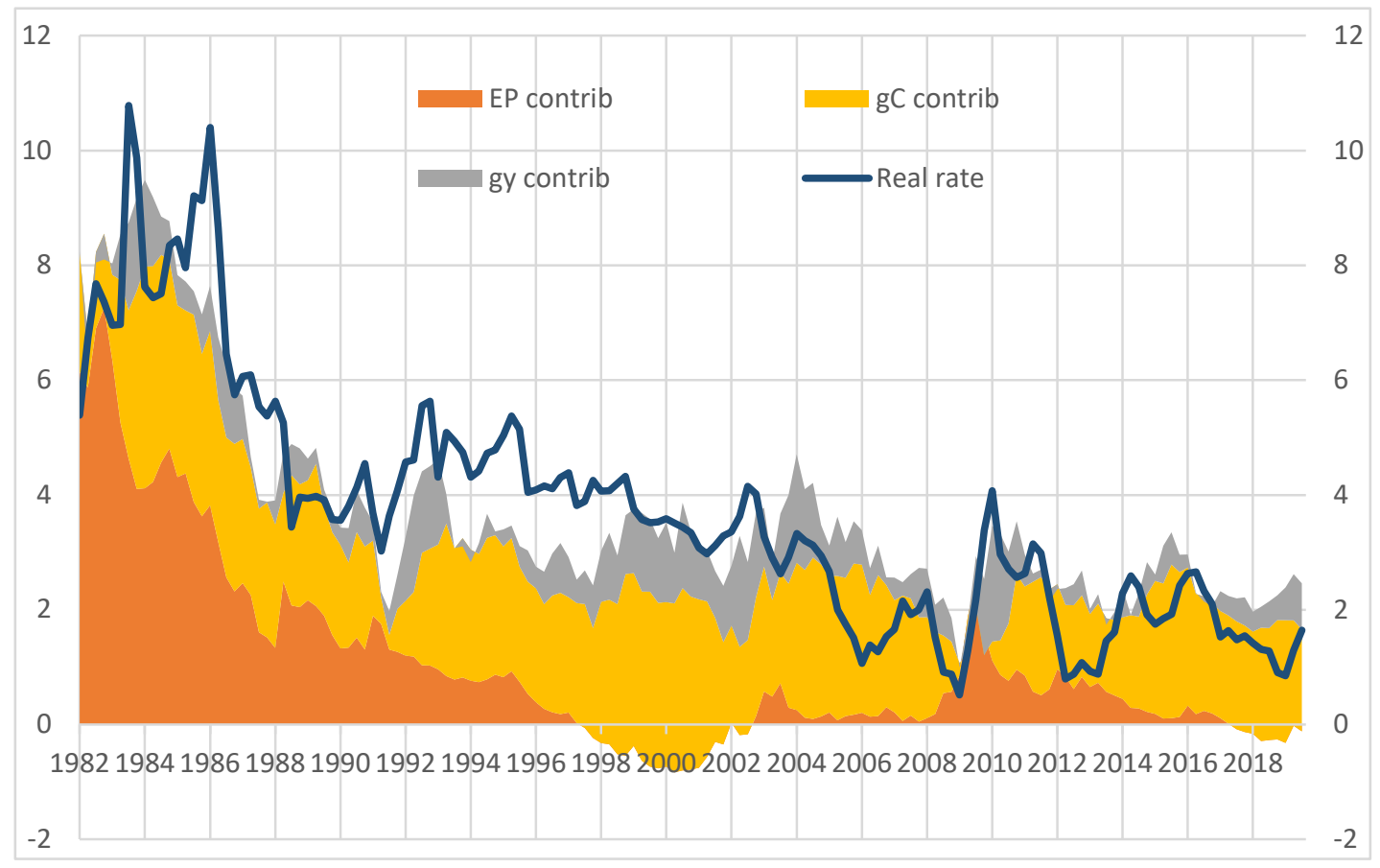

To summarize, we find that the EP ratio (that captures demographic change), productivity growth, and consumption growth emerge as significant determinants of the longrun real interest rate over the 1981:Q3 to 2019:Q1 period. The relative importance of the macroeconomic determinants changes over time, with the demographic factor mattering most in the 1981 to 1988 period and consumption growth most significant following recessions. 


\subsection{Principal components and long-run interest rates}

The analysis above focused on the long-run rate and its determinants. We now turn to an analysis of the yield curve, which conveys information both about the interest rate on longterm bonds as well as the compensation investors demand for holding a 10-year bond relative to holding bonds with shorter maturities (i.e., the term structure). By making use of the full yield curve it is possible to extract a set of factors that captures interest rate dynamics in both the short and the long run.

Litterman and Scheinkman (1991) proposed a technique for summarizing the yield curve with common factors that account for comovement of yields at different maturities. A common approach is to construct these common factors using principal component analysis. The principal components are linear combinations of yields at different maturities that account for the maximum portion of the variance-covariance matrix of yields. Constructing the principal components amounts to finding a rotation that diagonalizes the variance-covariance matrix of a panel of yield curves.

We extract principal components on U.S. yield curves from quarterly data over the 1981:Q3-2019:Q1 sample period. Our results are comparable to what is typically found in the literature. The first principal component accounts for almost all of the variation in yields (98.1\%), while the second and third principal components account for $1.5 \%$ and $0.4 \%$ of the variation, respectively. The variation accounted for by additional components are at least an order of magnitude smaller so we drop them from our discussion. 
Figure 7. Three principal components of U.S. yields, 1981:Q3-2019:Q1.
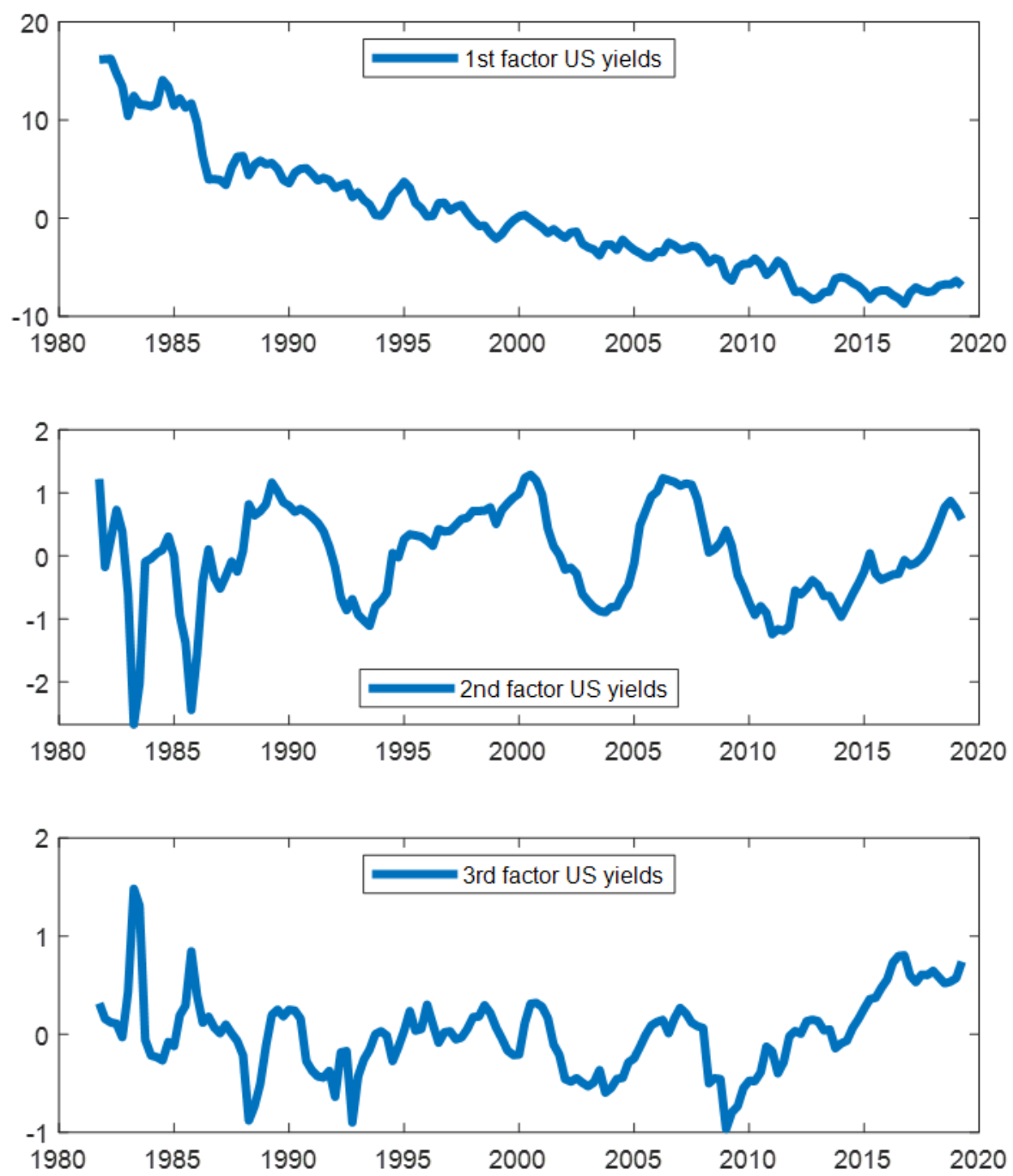

Figure 7 depicts the time series for the three principal components. The first component has a clear downward time trend. Over this period nominal interest rates were falling as was the rate of inflation. The fact that so much of the comovement in yield curves is captured by a secular downward trend is an indication that the low frequency drivers of the interest rate discussed above have a reasonable chance of explaining yield curves since the early 1980 s.

The second component is harder to interpret, with sharp swings and an irregular cyclical pattern between the 1980s and later in the sample. It has been suggested that the second 
component is related to the business cycle (e.g., Abbritti et al. 2018). The troughs in the second component occur in 1983:Q1, 1985:Q3, 1993:Q2, 2003:Q3, and 2010:Q4, roughly two years following a recession. It appears that there may be a connection to business-cycle downturns, though the connection is tenuous.

The third component exhibits fluctuations at a higher frequency. Note that although the second and third components explain less of the variation in yield curves in the estimation sample, this does not preclude the possibility that these factors are important for forecasting yields out of sample. For example, information that the economy may be shifting out of a boom into a recession may have only a slight impact on the trend, but could well be picked up by the second or third components and, therefore, could help forecast short-term yields.

Figure 8. Loadings $b_{n}$ on the first (level), second (slope) and third (curvature) principal components as functions of maturity, $n$.

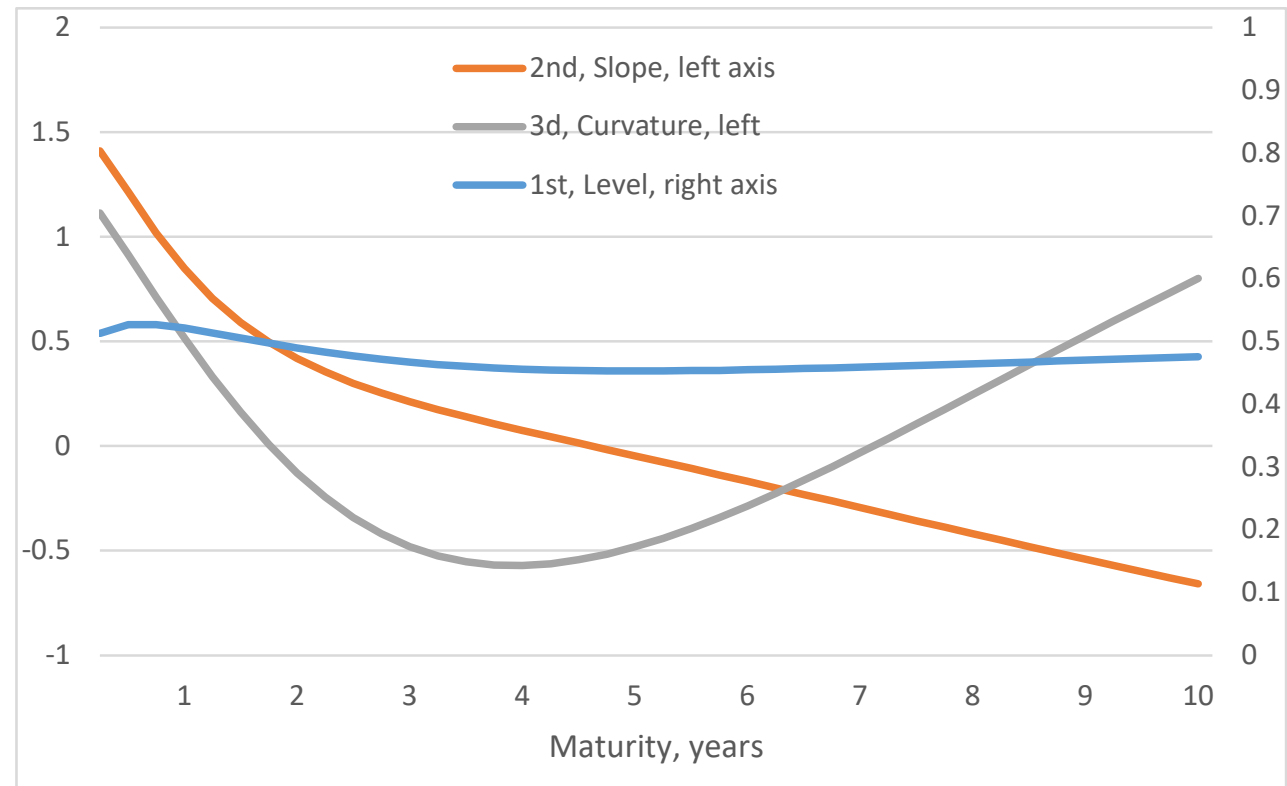


We next estimate the "factor loadings" of each component by running a regression of yields on the three principal components:

$$
y_{n, t}=a_{n}+b_{1, n} X_{1, t}+b_{2, n} X_{2, t}+b_{3, n} X_{3, t}+\varepsilon_{n, t}
$$

This is done for yields of different maturities. The loadings are plotted in Figure 8 for maturities ranging from one month to 10 years. The first loading, $b_{1, n}$, (for each maturity $n$ ) is shown by the blue line. It is quite flat, indicating that most of the variation in yields can be explained by a factor that shifts the entire yield curve and is, therefore, often referred to as a "level factor." The second factor (the orange line) has a loading that is high at short maturities and low at long maturities. This factor is referred to as a "slope factor," and a rise in this factor will make the yield curve flatter as it will raise short-term yields more than long-term yields. The third factor (in gray), the "curvature factor," is higher at short- and long- maturities and lowest at middle maturities of three to six years.

The principal components are a statistical method of describing patterns in yield curves. The components have no economic content in and of themselves. An interesting question, and one frequently asked in analyses of this type, is whether the principal components reflect a relationship between changes in macroeconomic variables that could be used to better understand the dynamics of yields in sample, as well as for forecasting out of sample. To this end, we examine whether the macroeconomic variables we found to be statistically significant for explaining the long-run interest rate in the previous section are associated with the principal components. To show this, we extract the principal components from a set of 151 yield curves over the 1981:Q3 to 2019:Q1 period and regress those components on the same set of variables as in Table 3. 
The results are shown in Table 4. The regression coefficients have the same units as the standard deviation of the first principal component. For example, according to the estimates in the table, a $1 \%$ permanent rise in private consumption expenditure shifts the first principal component of yields up by about one-fifth of its standard deviation. Note that the smoothing weight for inflation is kept the same as in the previous specification. This means that we are not imposing that inflation be neutral, and we allow the principal components to reveal the impact of inflation on the nominal interest rate at different maturities.

The first panel of Table 4 shows the coefficients of a regression of the first principal component on macroeconomic variables. The $R^{2}$ on this regression is high at 0.87 , an indication that the macroeconomic variables are successful in capturing the in-sample variation in yields. An increase in each of these variables results in a significant shift in the yield curve, with inflation having the largest elasticity, followed by consumption and the $E P$ ratio.

Macroeconomic variables explain much less of the variance in the second and third principal components of yields (the second and third panels of the table). Inflation enters with a positive coefficient, indicating that a rise in inflation will have a stronger, positive impact on the yield curve at shorter maturities. The $E P$ ratio has the opposite sign, perhaps an indication that an $E P$ ratio makes the yield curve steeper. The third principal component is explained most strongly by consumption growth.

To summarize, principal components analysis of U.S. yield curves over the 1981:Q3 to 2019:Q1 period generates the standard result that the first component accounts for almost all of the yield variations. The first component has a clear downward time trend, consistent with falling nominal rates and a declining rate of inflation over this period. We find strong evidence of a relationship between the first principal component and the macroeconomic drivers 
discussed in Section 2. That is, level shifts in the yield curve are largely driven by changes in inflation, consumption growth, and the EP ratio.

Table 4. Decomposition of the first three principal components of yields.

\begin{tabular}{|c|c|c|c|c|c|}
\hline $\begin{array}{l}1^{\text {st }} \text { principal } \\
\text { component of yields }\end{array}$ & $\beta_{\pi}(\omega=0.6)$ & $\boldsymbol{\beta}_{C}$ & $\beta_{y}$ & $\boldsymbol{\beta}_{E P}$ & $\boldsymbol{\beta}_{0}$ \\
\hline Coeff. & 0.45 & 0.20 & 0.13 & 0.16 & -3.02 \\
\hline Std. error & 0.04 & 0.03 & 0.02 & 0.02 & 0.11 \\
\hline$R^{2}=0.87$ & $N=151$ & & & & \\
\hline $\begin{array}{l}2^{\text {nd }} \text { principal } \\
\text { component of yields }\end{array}$ & $\beta_{\pi}(\omega=0.6)$ & $\beta_{C}$ & $\beta_{y}$ & $\beta_{E P}$ & $\beta_{0}$ \\
\hline Coeff. & 0.59 & -0.06 & -0.01 & -0.30 & 0.18 \\
\hline Std. error & 0.09 & 0.07 & 0.05 & 0.04 & 0.27 \\
\hline$R^{2}=0.26$ & $N=151$ & & & & \\
\hline $\begin{array}{l}3^{\mathrm{d}} \text { principal } \\
\text { component of yields }\end{array}$ & $\beta_{\pi}(\omega=0.6)$ & $\beta_{C}$ & $\beta_{y}$ & $\beta_{E P}$ & $\beta_{0}$ \\
\hline Coeff. & -0.05 & 0.39 & -0.20 & 0.01 & -0.60 \\
\hline Std. error & 0.10 & 0.08 & 0.05 & 0.05 & 0.28 \\
\hline$R^{2}=0.19$ & $N=151$ & & & & \\
\hline
\end{tabular}

\subsection{Results from the dynamic model}

An advantage of using the full yield curve is that it has the potential to reveal information not only about the interest rate levels but also about the dynamic adjustment of interest rates to shocks. We implement a dynamic reduced form affine term structure model with a set of three latent variables stacked into a (3X1) vector $X_{t}$ and three economic indicators in a separate (3X1) vector $F_{t}$. The model is similar to that in Abbritti et al. (2018) but the state vector is different. ${ }^{9}$ The latent variables are the three principal components of the yield curves from three months to 10 years maturity. The model's equations are

$$
y_{n, t}=a_{n}+b_{n} X_{t}
$$

\footnotetext{
${ }^{9}$ We thank Mirko Abbritti for sharing the MATLAB code for estimating the model. We report results with indirect-inference bias correction (Bauer et al. 2012).
} 


$$
\begin{gathered}
X_{t}=\Phi X_{t-1}+\Lambda F_{t}+v_{t} \\
F_{t}=\Gamma F_{t-1}+\eta_{t}
\end{gathered}
$$

We assume that the shocks to economic indicators, $\eta_{t}$, and the shocks to the principal components, $v_{t}$ are uncorrelated. We estimate $\left(\Lambda, \Phi, \Gamma, \Sigma_{v}, \Sigma_{\eta}\right)$ with ordinary least squares (OLS) and indirect-inference bias correction. The term structure model allows us to ask, what is the role of various macroeconomic indicators in explaining the dynamics of yield curves, after accounting for the role of the principal components? In particular, the vector autoregression (VAR) shows the change in yields at different maturities and the rate at which that impact dies out over time.

\subsubsection{U.S. economic indicators}

We estimate the dynamic model with U.S. economic indicators using the 1981:Q3 to 2019:Q1 sample, the longest time period for which both inflation and consumption growth forecasts are available. The addition of shocks raises the complexity of the estimation procedure at an exponential rate, so we limit the set of economic indicators to three. In the first set, we include the $E P$ ratio, consumption growth, and inflation, where consumption growth and inflation are again smoothed. In the second set of indicators, we replace the EP ratio with productivity growth, that is

$$
F_{t}^{1}=\left[\begin{array}{c}
E P_{t} \\
g_{C, t} \\
\pi_{t}
\end{array}\right] \text {, and } F_{t}^{2}=\left[\begin{array}{c}
g_{y, t-4} \\
g_{C, t} \\
\pi_{t}
\end{array}\right] .
$$

Figure 9 depicts the impulse response of yields at different maturities to a one standard deviation shock to each of the three indicators. The figures show the estimated response of yields to innovations in the particular indicator at different maturities (one-year, three-year and 10 -year) and at different horizons (zero to 20 years). For example, the yellow line in the left- 
most panel of Figure 9 shows that a rise in the EP ratio has little effect on the 10-year rate on impact. In addition, the VAR does not pick up dynamic effects of the EP ratio on the 10-year rate over time, as the rate is not affected at out-horizons of five to 20 years. There does appear to be a weak, negative relationship between the EP ratio and short-term yields of one to five years, which turn positive at a five-year horizon.

Consumption growth, the middle panel of Figure 9, has a strong, positive effect on yields, with the largest impact on the very short end of the yield curve. The impact on all yields is strongest at the three-year horizon and then quickly dies out. The dynamic response of yields to innovations in inflation is weak with most of the action in the one-year rate.

Figure 9. Impulse responses to yields to $F_{t}^{1}$ indicators
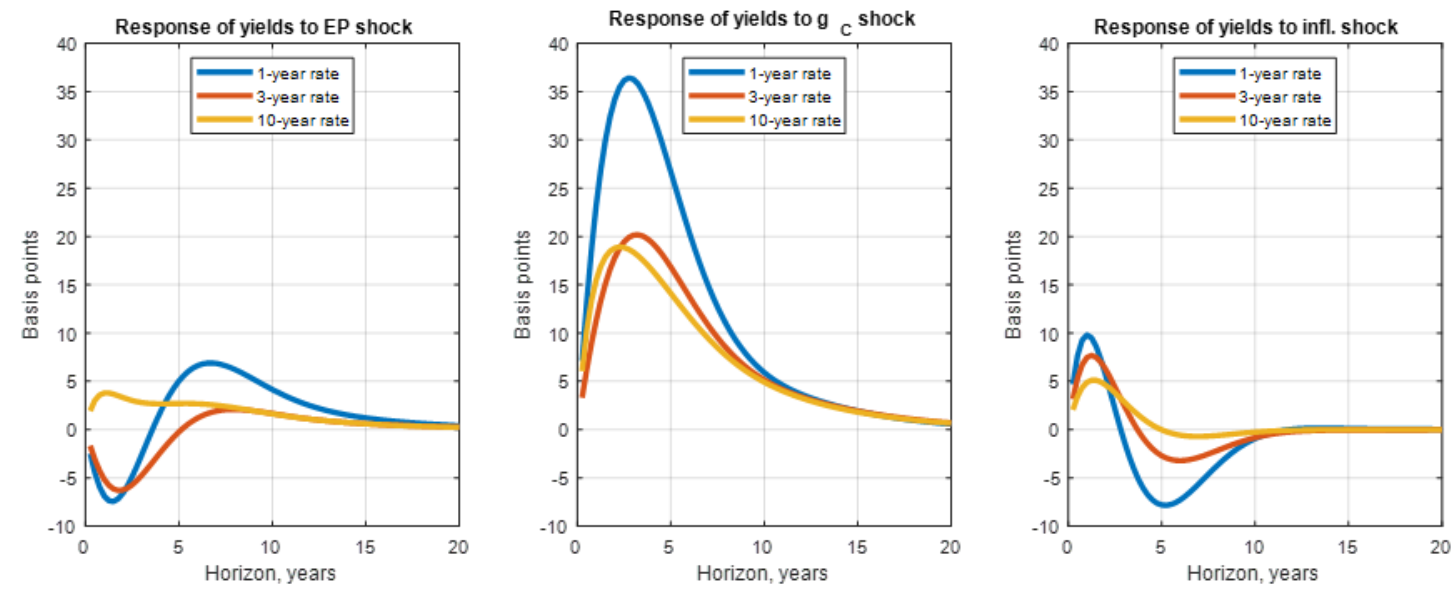

Figure 10 plots the variance decomposition that shows the percent of yield variance explained by each indicator in $F_{t}^{1}$ at different forecasting horizons. The purple line shows the percent of variance explained by all three indicators together. Looking across the figures we see that consumption growth (the red line) explains up to $60 \%$ of the variance of short-term yields, even at a 10-year forecast horizon. The $E P_{t}$ and $\pi_{t}$ indicators explain almost none of the variance, an indication that neither of these variables adds information for forecasting 
beyond what is already contained in the cross-section of yields and summarized by the three principal components in $X_{t}$.

Figure 10. Variance decomposition for $F_{t}^{1}$ indicators.
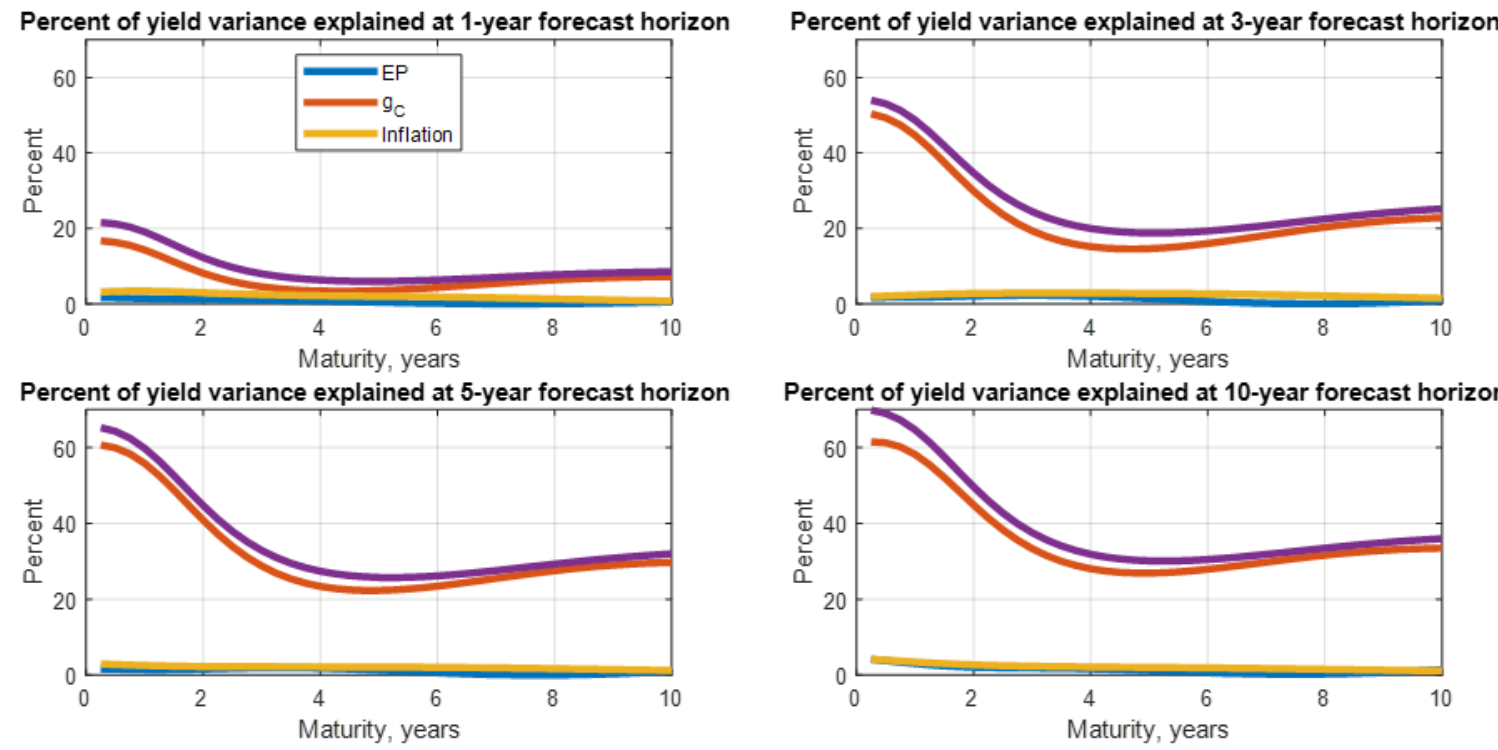

We next consider a triple of indicators $F_{t}^{2}$ consisting of U.S. productivity growth, consumption growth, and inflation. Productivity growth (now in place of the $E P$ ratio) has a significant, positive effect on yields at all maturities at the one- to 10-year forecasting horizon. The impulse responses to consumption growth are little changed relative to the previous VAR specification, although the magnitude of the effects are slightly smaller. The inflation indicator now comes in positive, moving all three yields and peaking at the two — to three-year horizon. 
Figure 11. Impulse responses to yields to $F_{t}^{2}$ indicators.
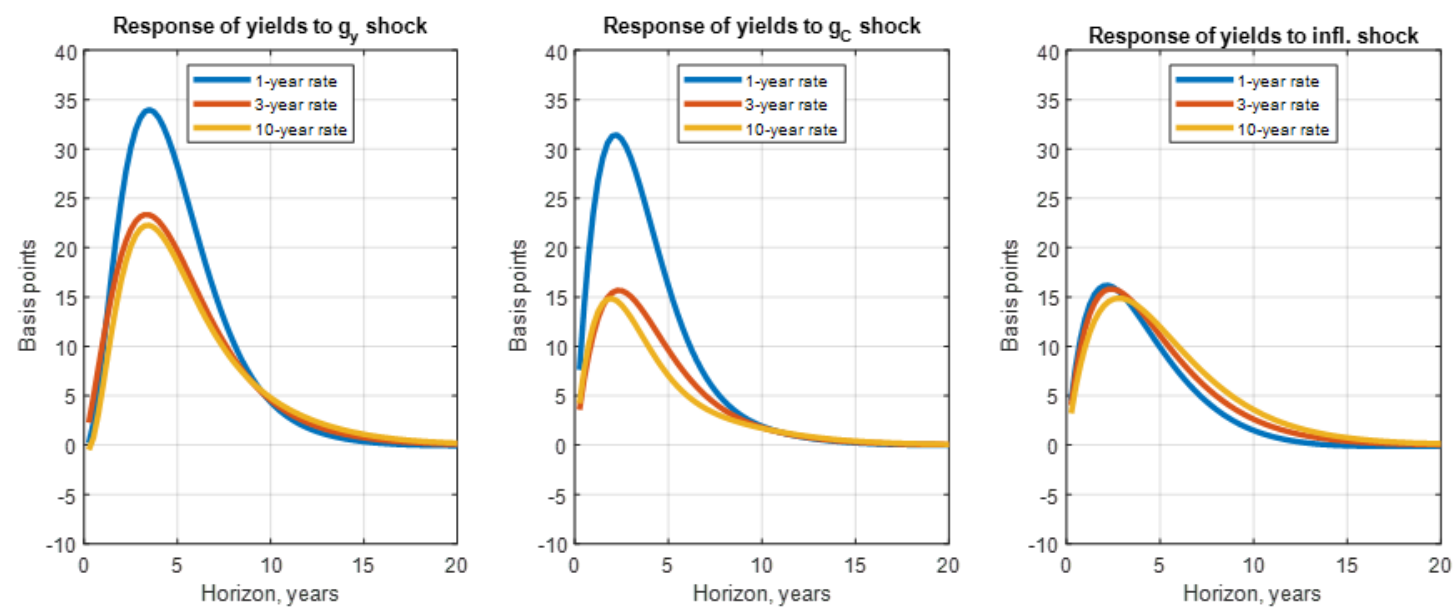

Figure 12 (analogous to Figure 10) shows the variance decomposition for the indicators in $F_{t}^{2}$. Relative to the previous VAR specification, we see that all three variables contain some information beyond the principal components. Together, the three indicators explain between 60 and $75 \%$ of yield variance at the short end of the yield curve, and between 30 and $50 \%$ of variance at the long end. Productivity growth now explains as much as $40 \%$ of the variance of yields, particularly at the longer forecast horizons. Consumption growth continues to pick up variance at the short end of the yield curve. The inflation indicator $\pi_{t}$ now explains up to $20 \%$ of the variance. 
Figure 12. Variance decomposition for $F_{t}^{2}$ indicators.
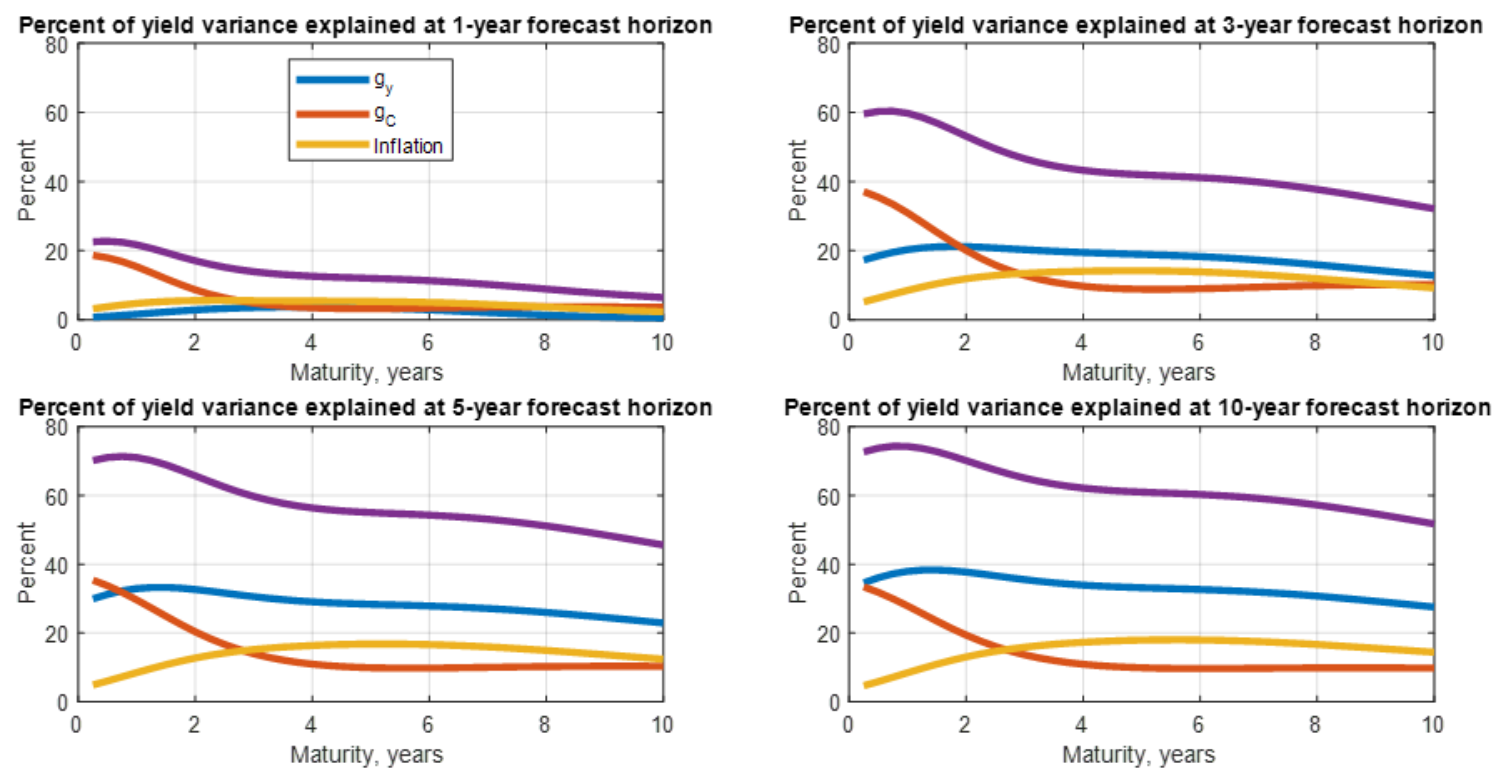

To summarize, there is little information in the $E P$ ratio beyond what is already captured by the principal components. In contrast, consumption growth and productivity growth play distinct roles in explaining the yield variances, with consumption growth being most important for short-term rates and productivity growth for both short- and long-term rates.

\subsubsection{Global economic indicators}

We now change the vector $F_{t}$ to include a set of leading indicators for global economic activity. In the previous section, we found that consumption growth was an important factor for explaining U.S. interest rates. We add to the vector OECD-constructed composites of leading economic indicators ${ }^{10}$ for the EU $\left(g_{E U}^{e}\right)$ and the major five Asian economies $\left(g_{A 5}^{e}\right)$ (China, India, Indonesia, Japan, and Korea - Asia-5). Our sample period is 1990:Q2 to 2019:Q1, starting

\footnotetext{
${ }^{10}$ Specifically, the indicator is the growth rate in the trend-restored composite leading indicator (CLI) from the prior quarter.
} 
with the earliest quarter when the Asian growth indicator is available. The underlying data in the composite indicators are selected based on broad coverage of current economic activity and as leading indicators of future real activity. Indicators include, for instance, activity at the early stages of production, factory orders, construction permits, measures of business confidence, and the like. The vector $F_{t}$ is defined:

$$
F_{t}^{3}=\left[\begin{array}{c}
g_{E U, t}^{e} \\
g_{A 5, t}^{e} \\
g_{C, t}
\end{array}\right] .
$$

Figure 13 shows the impulse responses of one-, three- and 10-year nominal yields to a one standard deviation structural shock to each of the three indicators.

Figure 13. Impulse responses
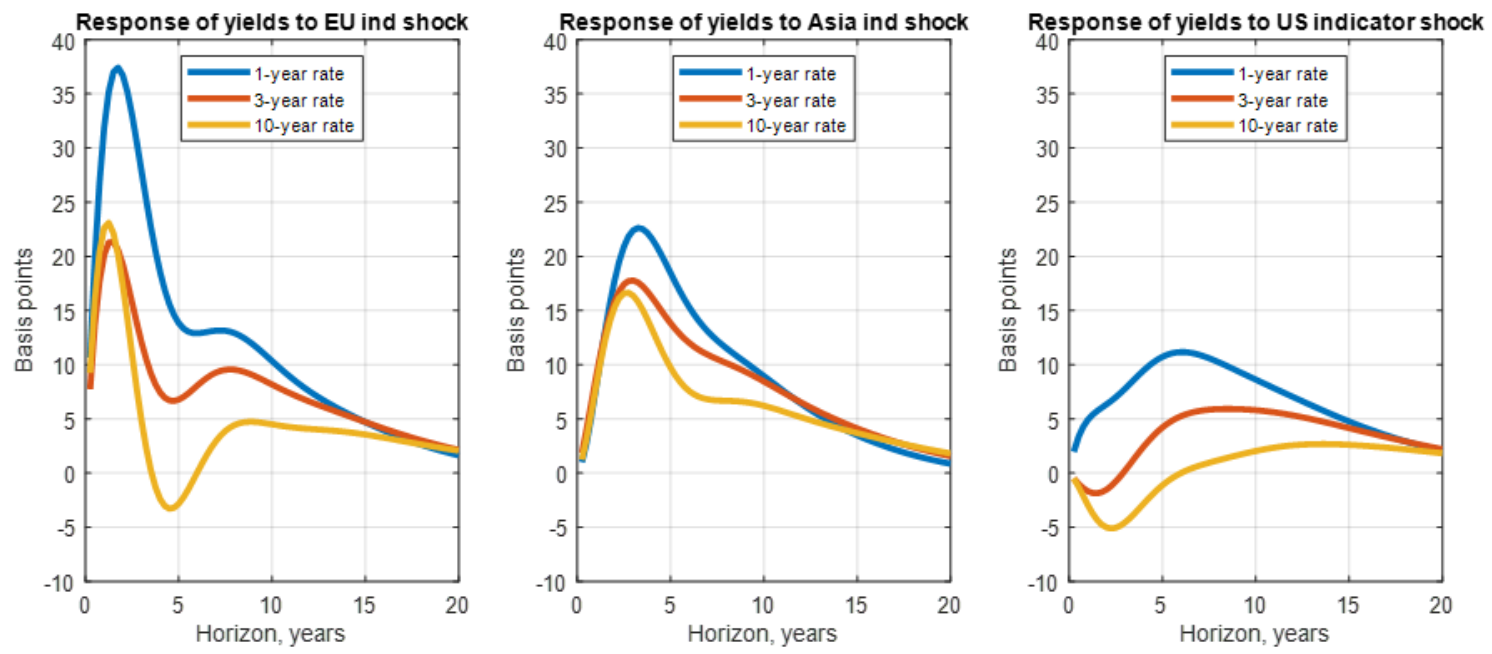

The impulse responses indicate that higher expected growth in the EU and Asia raise U.S. nominal interest rates and that the effects are quite persistent. The EU indicator is especially important for shifting short rates. Higher expected consumption in the U.S. raises short rates more than long rates, but the impulse response is small overall. The indicators are jointly significant with a $P$-value of $1.4 \cdot 10^{-5}$. 
Figure 14. Variance decomposition for $F_{t}^{3}$ indicators.
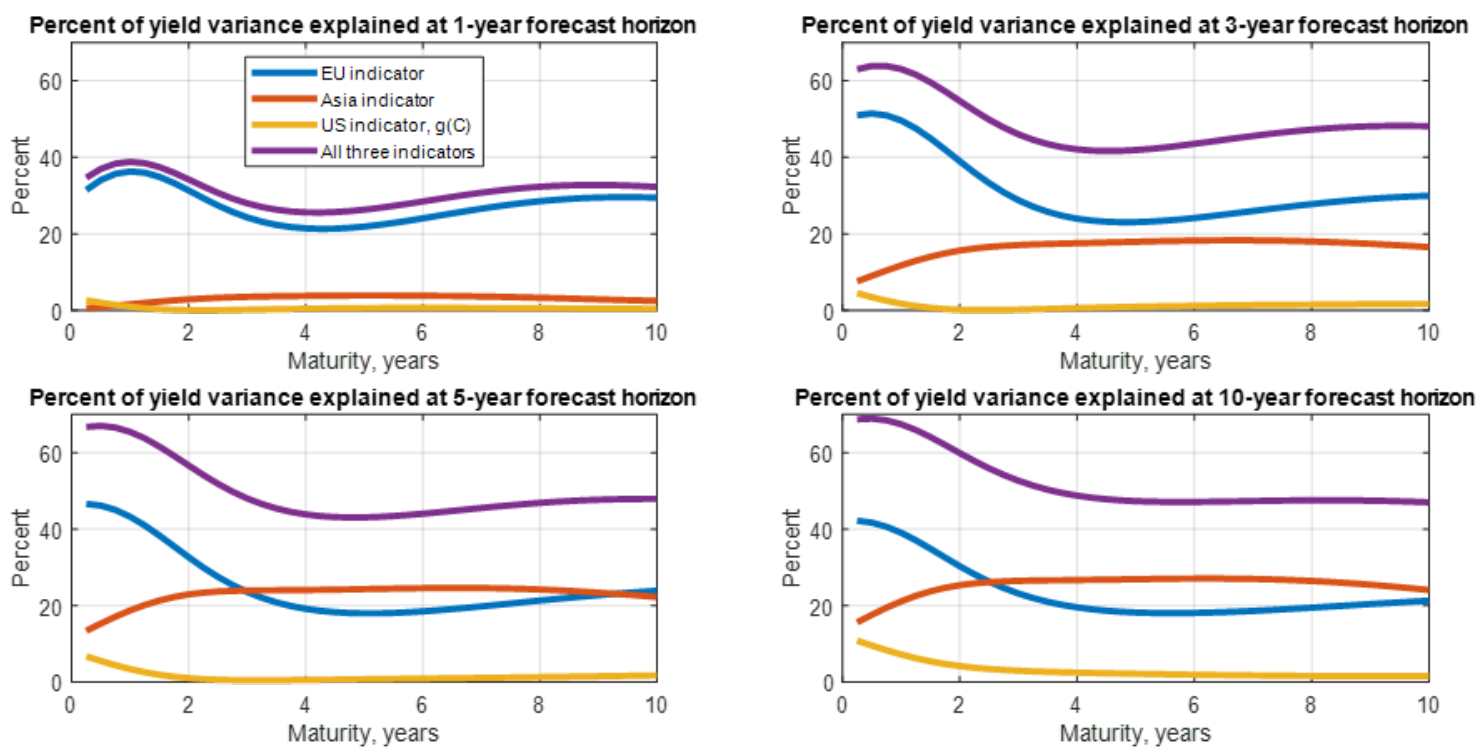

Figure 14 shows the variance decomposition. The EU indicator is dominant, especially at the short end of the yield curve, where it explains about $40 \%$ of the variance; the indicator for Asian economic activity explains about $20 \%$ of the variance at maturities of four to 10 years. Overall, the set $F_{t}^{3}$ with international variables explains a bit less variance in yields than the set $F_{t}^{2}$. The presence of $g_{E U, t}^{e}$ seems to reduce the ability of $g_{C, t}$ to explain yield variance. This is perhaps because the correlation between the two is 0.41 .

To summarize, three indicators, $g_{y, t-4}, g_{E U, t}^{e}$ and $g_{A 5, t}^{e}-$ all related to growth in output — emerge as reasonable candidates for explaining the variance of interest rates. The triple of economic indicators $F_{t}^{2}$ accounts for between 60 and $75 \%$ of yield variance at the short end of the yield curve, and between 30 and $50 \%$ of variance at the long end. These results are broadly consistent with Ang and Piazzesi (2003) who find that macroeconomic variables can account for a large portion of variance in yields, especially at the short end of the yield curve. 
Figure 15. Out-of-sample forecasting with domestic indicators.
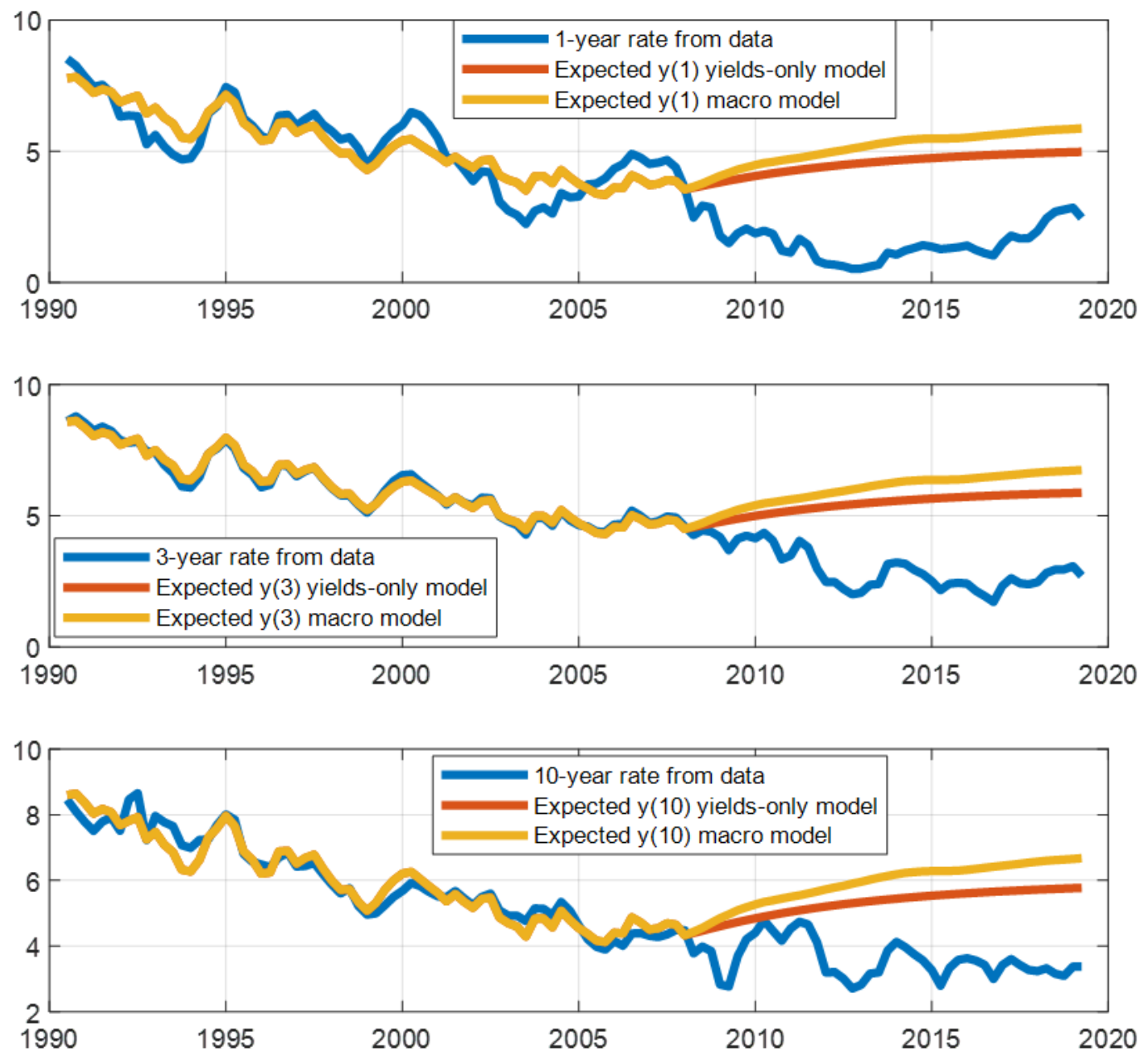

\subsubsection{Comparisons of forecasting performance}

Previous research demonstrated that changes in the level component of yields are not forecastable in a yields-only model (e.g., Duffee 2013). As discussed in the Section 3review of the literature on methods for forecasting interest rates, it remains an open question whether macroeconomic variables improve forecasts of interest rates once the information from yields is fully taken into account. We have found that there is a connection between macroeconomic variables and interest rate dynamics in sample. We now ask whether the addition of domestic and international variables improves the forecast out of sample. Accordingly, we use a six- 
factor macrofinance model that includes three principal components of yields and three additional macroeconomic indicators. We compare out-of-sample forecasting properties among the yields-only model (that is, a special case of (5) with $\Lambda=0$ ), the macrofinance model with domestic macroeconomic indicators $\left(F_{t}^{2}\right)$ and the macrofinance model with both global and domestic indicators $\left(F_{t}^{3}\right)$. Because most of the yield variation is captured by the first principal component, our comparisons focus on the models' ability to predict the level component of yields, $X_{1, t}$. For consistency, we estimate each of the three models using the 1990:Q2 to 2007:Q4 period, a subsample that includes the period prior to the great financial crisis. We show that the extended model can sometimes track the interest rate's falling trajectory much better than a yields-only model.

Without loss of generality, let $t=0$ denote the end of our sample period. To forecast the time path for $X_{t}$ using solely the information on the history of realizations of economic indicators $F_{1}, \ldots, F_{t}$, set $v_{t}=0$ for all $t \geq 0$ and iterate equation (5) forward from the initial condition $X_{0}$ taken from the data. In other words, we calculate a conditional expectation

$$
\hat{X}_{t}=\mathbb{E}\left(X_{t} \mid X_{0}, F_{1}, \ldots, F_{t}\right) .
$$

In the yields-only model, the forecast of $X_{t}$ is $\mathbb{E}\left(X_{t} \mid X_{0}\right)$. In the macrofinance model, by contrast, the forecast of $X_{t}$ is updated each period, using the most recent observation in $F_{t}$. 
Figures 15 and 16 compare the resulting trajectories for predicted yields. To isolate the impact of model specification on the level component of yields, the figures depict yields predicted with just the first principal component, according to

$$
\hat{y}_{n, t}=a_{n}+b_{1, n} \hat{X}_{1, t}
$$

instead of using all three components, as in equation (4). ${ }^{11}$

The interest rate forecast from the yields-only model (depicted by the orange line on the figures) based on information available at the end of 2007 shows the 10 -year nominal rate gradually rising from $4.3 \%$ in 2008 to about $5.8 \%$ by 2019 . The rising forecast trajectory looks similar to Blue Chip interest rate forecasts depicted on Figure 4.

Comparing Figures 15 and 16, we can see that forecasting performance changes substantially depending on the set of macroeconomic indicators. The specification of the macrofinance model with economic indicators, $F_{t}^{2}$, that includes U.S. labor productivity growth and the weighted averages of forecasted and past year's consumption growth and inflation not only fails to capture the falling trajectory for the interest rate after 2008, but also does worse than the yield only model. ${ }^{12}$ We think that this may have to do with the (wrong) sign for the coefficient on inflation in the first row of the estimated $\Lambda$ matrix in (5). Since inflation after the global financial crisis was generally below average, the model's forecast for the interest rate would tend to be high. By contrast, the macrofinance model with EU and Asia-5 leading

\footnotetext{
${ }^{11}$ Given our regression results in Table 4, one should not expect information contained in $F_{t}$ to produce high-quality forecasts of the second and third principal components. The estimates of the dynamic model bear this out. Forecasts of $\hat{X}_{2, t}, \hat{X}_{3, t}$ from (6) are, in fact, volatile, and so are predicted yields calculated from (4).

${ }^{12}$ The interest rate level component forecasted with $F_{t}^{1}$ indicators is qualitatively similar to that depicted on Figure 15 - the expected interest rate trajectory is higher than that from the yields-only model.
} 
indicators tracks the interest rate levels much better out-of-sample. It seems that information contained in the OECD regional leading indicators is relevant for predicting interest rate levels.

It is not entirely clear why the macrofinance model with global factors tracks the level component of yields better than the model with domestic factors. One hypothesis may be that domestic macroeconomic conditions are priced into yields to a larger extent than global conditions. If true, the coefficients of the matrix $\Lambda$ will not fully capture the links between domestic macroeconomic conditions and yields, as some of that information could already be encoded into the principal components $X_{t}$. Our out-of-sample forecasting exercise does not use out-of-sample information on $X_{t}$ but it does use the out-of-sample information on $F_{t}$. By contrast, if global macroeconomic indicators are priced into yields to a smaller extent, the model would capture less feedback between the global indicators in $F_{t}$ and the principal components.

Another hypothesis may be a regime change with respect to inflation after the global financial crisis, which would make a stationary VAR an inappropriate model of yield dynamics, especially when inflation-related variables are included in the state vector $F_{t}$.

To summarize, the comparison exercise in this section illustrates that global macroeconomic indicators hold some promise in forecasting interest rates out of sample. Our preliminary analysis suggests that information about expected growth in other large economies has relevance in explaining U.S. interest rate shifts. 
Figure 16. Out-of-sample forecasting with global and domestic indicators.
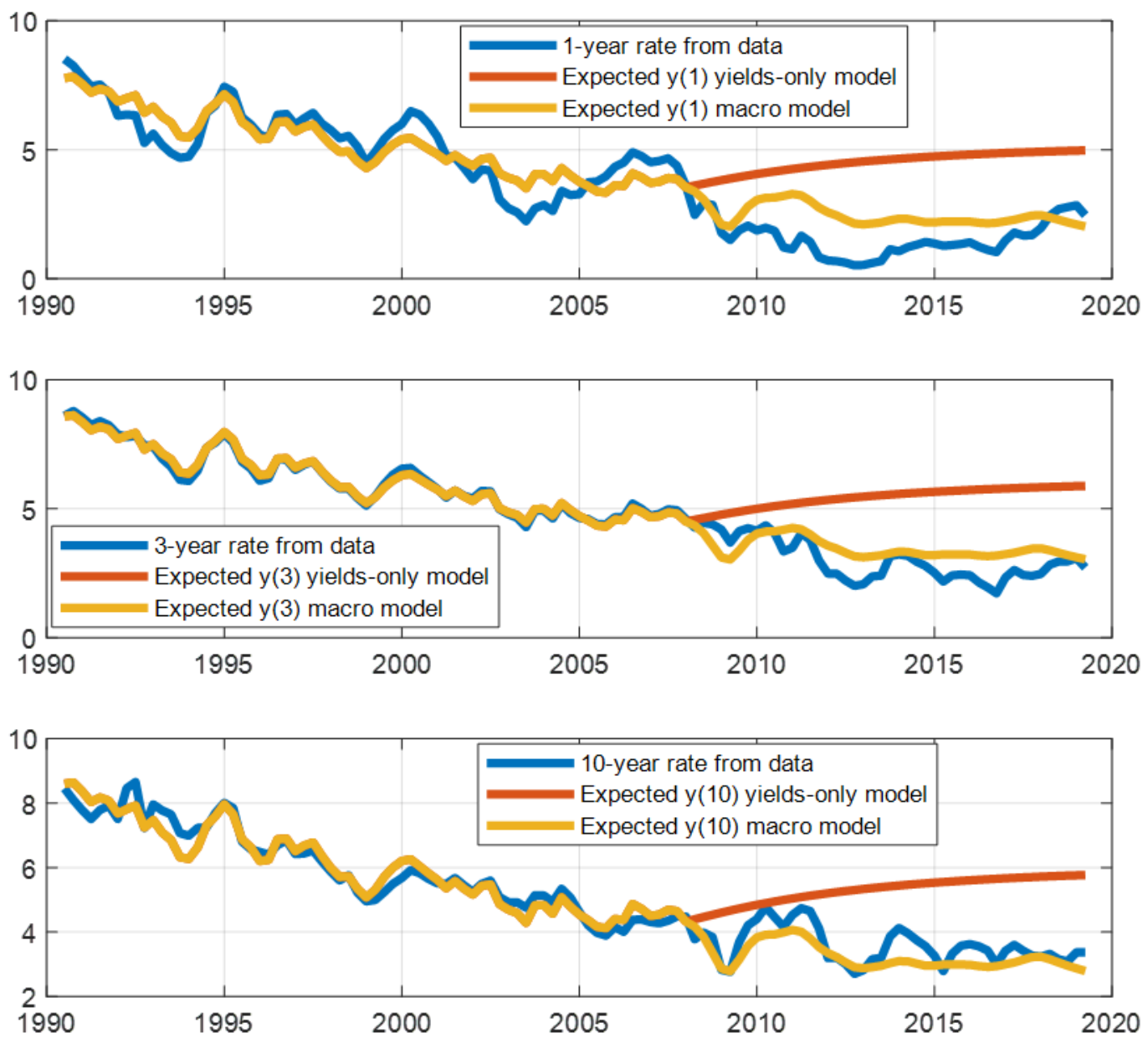

\subsubsection{Forecasting international yields}

Given our finding that information from international markets has an impact on U.S. interest rate dynamics, it is natural to ask whether global economic indicators are significant for the dynamics of other countries' yields as well. To answer this question, we construct countryspecific sets of principal components of yields for Germany, U.K., and Canada and re-estimate the dynamic model of Section 4.3. We perform the estimation separately for each country using a country-specific series for $X_{t}$ and a common series for global economic indicators, $F_{t}^{4}$. 
We evaluate the relevance of global indicators for foreign countries' yield dynamics with variance decompositions similar to those shown on Figures 15 and 16.

For consistency, the set $F_{t}^{4}=\left[g_{E U, t}^{e}, g_{A 5, t}^{e}, g_{U S, t}^{e}\right]^{\prime}$ includes only OECD-sourced composite leading indicators for the EU, Asia-5, and the U.S. The results from the variance decomposition are generally encouraging, and they are broadly similar to those presented in Figure 14. One regularity is that the EU indicator well explains yield variances at the short end of the yield curve. This result appears robust across countries and subsamples. The portion of short rate variance that the EU indicator explains varies significantly by country: This portion is 30 to $50 \%$ for the U.S., 30 to $60 \%$ for Germany and the U.K. and only 10 to $30 \%$ for Canada. The Asia-5 indicator, by contrast, explains the largest portion of the variance at the longer end of the yield curve, however, its ability to pick up yield variance depends on the estimation subsample. The Asia-5 indicator appears to be much more relevant in the pre-great financial crisis subsample, 1990:Q2 to 2007:Q4. We think that this is because the correlation between the EU and Asia-5 indicators increased after 2008, suggesting that the two no longer contain as much distinct information over the later segment of the sample. For similar reasons, the U.S. composite leading indicator does not explain much of yield variance in any of the four countries. This may be because of its high correlation with the EU indicator, which is 0.73 over the full sample.

To summarize, global economic indicators, especially the composite leading indicator for the EU, are capable of accounting for a large portion of yield variance not only in the U.S. but in other advanced economies as well. Changes in global real activity, as captured by three composite leading indicators, account for most of the variance in the short rates and a somewhat smaller portion of the variance in long rates. 


\section{Conclusion}

The goal of this paper is two-fold: first to provide a synthesis of methodologies for constructing long-range interest rate projections and second, to examine the role of domestic and global macroeconomic variables in forecasting U.S. interest rates.

This paper reviewed a number of methodologies for constructing long-range interest rate projections. Traditional statistical forecasting models based on stationary VAR dynamics face some limitations in their ability to capture low-frequency movements in interest rates, at least with available sample lengths of 150 quarters or so. Several other methodologies for long-range interest rate projections - particularly, those that can make use of long time series may complement the insights from forecasting models.

Two methodologies are potentially useful for constructing long-range interest rate projections: semistructural methods of interest rate trend decomposition and standard statistical forecasting models with an extended set of explanatory variables, including forwardlooking economic indicators. These methodologies use different data and samples, and they provide complementary pieces of information. Moreover, interest rate trend decompositions are potentially informative on the state variables set that may be included in a VAR-based forecasting model.

We perform a decomposition of the long-run nominal interest rate over the period 1981 to 2019 under the assumption that, in the long-run, inflation has no effect on the real interest rate. Three variables, the earnings-price ratio of the stock market, the weighted average of past and forecasted consumption growth, and year-on-year productivity growth explain $87 \%$ of variation in the 10-year real rate. The relative importance of the various macroeconomic 
determinants changes over time, with the earnings-price ratio mattering most in the 1981 to 1988 period and consumption growth most significant following recessions.

Our reduced-form decomposition and interpretation of results in Del Negro et al. (2018) and Gourinchas and Rey (2019) suggest global macroeconomic variables as well as forwardlooking indicators as good candidates for the expanded set of explanatory variables in a forecasting model. An important and unresolved question in the literature is whether macroeconomic-conditions information improves the forecast for interest rates, or whether past yield information is sufficient to fully characterize interest rate dynamics. We add to this debate by exploring the role of domestic and international macroeconomic variables for interest rate forecasting. We find that international variables are increasingly important for understanding and predicting U.S. interest rates.

To assess the forecasting performance of global and domestic indicators, we estimate a macrofinance affine term structure model. This method allows us to ask whether macroeconomic variables add information after conditioning on past information about yields captured by the principal components. Our estimates show there is little information in the earnings-price ratio beyond what is already encoded in the principal components of yields. In contrast, U.S. consumption growth and productivity growth play distinct roles in explaining the variance of yields, with consumption growth being most important for short-term rates, and productivity growth for both short- and long-term rates. We find that growth indicators for Europe and Asia are strongly significant, supporting our view that international factors are increasingly important for U.S. interest rate determination.

An important contribution of our work is the addition to the forecast of international, forward-looking indicators. We compare the out-of-sample forecasting properties of the 
dynamic model under three specifications: a yields-only model, a macrofinance model with domestic macroeconomic indicators, and a macrofinance model both domestic and international indicators. We find that the model with international factors can outperform the other models by better tracking the falling trajectory of U.S. interest rates in the post-2008 period, a trend that is missed by domestic variables. Further, we find that global economic indicators, especially the composite leading indicator for the EU, are capable of accounting for a large portion of yield variance not only in the U.S. but in other advanced economies as well. 


\section{References}

Abbritti, Mirko, Salvatore Dell'Erba, Antonio Moreno, and Sergio Sola, "Global Factors in the Term Structure of Interest Rates." International Journal of Central Banking, Vol. 14 No. 2 (March 2018): 301-339. https://doi.org/10.5089/9781475513516.001.

Adrian, Tobias, Richard K. Crump, and Emanuel Mönch. "Pricing the Term Structure with Linear Regressions." Journal of Financial Economics 110, no. 1 (October 1, 2013): 110 38. https://doi.org/10.1016/i.jfineco.2013.04.009.

Ang, Andrew, and Monika Piazzesi. "A No-Arbitrage Vector Autoregression of Term Structure Dynamics with Macroeconomic and Latent Variables." Journal of Monetary Economics 50, no. 4 (May 1, 2003): 745-87. https://doi.org/10.1016/S0304-3932(03)00032-1.

Baker, Dean, J. Bradford De Long, and Paul R. Krugman. "Asset Returns and Economic Growth." Brookings Papers on Economic Activity 2005, no. 1 (2005): 289-330.

Bauer, Michael D., Glenn D. Rudebusch, and Jing Cynthia Wu. "Correcting Estimation Bias in Dynamic Term Structure Models." Journal of Business \& Economic Statistics 30, no. 3 (July 1, 2012): 454-67. https://doi.org/10.1080/07350015.2012.693855.

Barro, Robert J., and Gary S. Becker. "Fertility Choice in a Model of Economic Growth." Econometrica 57, no. 2 (1989): 481-501. https://doi.org/10.2307/1912563.

Blanchard, Olivier, "Public debt and low interest rates," American Economic Review (2019) forthcoming.

Bloom, Nicholas, Erik Brynjolfsson, Lucia Foster, Ron S. Jarmin, Megha Patnaik, Itay SaportaEksten, and John Van Reenen. 2014. "IT and Management in America." CEPR Discussion Paper, DP9886.

Caballero, Ricardo J., Emmanuel Farhi, and Pierre-Olivier Gourinchas. "An Equilibrium Model of 'Global Imbalances' and Low Interest Rates." American Economic Review 98, no. 1 (March 2008): 358-93. https://doi.org/10.1257/aer.98.1.358. 
Caballero, Ricardo J., Emmanuel Farhi, and Pierre-Olivier Gourinchas. "The Safe Assets Shortage Conundrum." Journal of Economic Perspectives 31, no. 3 (August 2017): 29 46. https://doi.org/10.1257/jep.31.3.29.

Carvalho, Carlos, Andrea Ferrero, and Fernanda Nechio. "Demographics and Real Interest Rates: Inspecting the Mechanism." European Economic Review, SI: The Post-Crisis Slump, 88 (September 1, 2016): 208-26.

https://doi.org/10.1016/j.euroecorev.2016.04.002.

Coroneo, Laura, Domenico Giannone, and Michele Modugno. "Unspanned Macroeconomic Factors in the Yield Curve." SSRN Scholarly Paper. Rochester, NY: Social Science Research Network, July 30, 2014. https://papers.ssrn.com/abstract=2480081.

Dai, Qiang, and Kenneth J. Singleton. "Specification Analysis of Affine Term Structure Models." The Journal of Finance 55, no. 5 (2000): 1943-78.

https://doi.org/10.1111/0022-1082.00278.

Del Negro, Marco, Domenico Giannone, Marc P Giannoni, and Andrea Tambalotti. "Global Trends in Interest Rates." Working Paper. National Bureau of Economic Research, September 2018. https://doi.org/10.3386/w25039.

Diebold, Francis X., and Canlin Li. "Forecasting the Term Structure of Government Bond Yields." Journal of Econometrics 130, no. 2 (February 1, 2006): 337-64. https://doi.org/10.1016/j.jeconom.2005.03.005.

Diebold, Francis X., Canlin Li, and Vivian Z. Yue. "Global Yield Curve Dynamics and Interactions: A Dynamic Nelson-Siegel Approach." Journal of Econometrics, Honoring the research contributions of Charles R. Nelson, 146, no. 2 (October 1, 2008): 35163.https://doi.org/10.1016/j.jeconom.2008.08.017.

Domanski, Dietrich, Emanuel Kohlscheen, and Ramon Moreno. "Foreign Exchange Market Intervention in EMEs: What Has Changed?" September 18, 2016. https://www.bis.org/publ/qtrpdf/r qt1609f.htm. 
Duffee, Gregory R. "Information in (and Not in) the Term Structure." The Review of Financial Studies 24, no. 9 (September 1, 2011): 2895-2934. https://doi.org/10.1093/rfs/hhr033.

Duffee, Gregory, 2013. "Forecasting Interest Rates", Handbook of Economic Forecasting, Volume 2, Part A, Graham Elliott, Allan Timmermann, eds., pp. 385-426 https://doi.org/10.1016/B978-0-444-53683-9.00007-4.

Duffie, Darrell, and Rui Kan. "A Yield-Factor Model of Interest Rates." Mathematical Finance 6, no. 4 (1996): 379-406. https://doi.org/10.1111/j.1467-9965.1996.tb00123.x.

Fama, Eugene F., and Robert R. Bliss. "The Information in Long-Maturity Forward Rates." The American Economic Review 77, no. 4 (1987): 680-92

Favero, Carlo A., Arie E. Gozluklu, and Haoxi Yang. "Demographics and the Behavior of Interest Rates." IMF Economic Review 64, no. 4 (November 1, 2016): 732-76. https://doi.org/10.1057/s41308-016-0020-2.

Geanakoplos, John, Michael Magill, and Martine Quinzii. "Demography and the Long-Run Predictability of the Stock Market." Brookings Papers on Economic Activity 2004, no. 1 (2004): 241-325. https://doi.org/10.1353/eca.2004.0010.

Gordon, Robert J. 2010. "Revisiting U.S. Productivity Growth over the Past Century with a View of the Future." NBER Working Paper, 15834.

Gourinchas, Pierre-Olivier, and Hélène Rey. "Global Real Rates: A Secular Approach," July 4, 2019. https://www.bis.org/publ/work793.htm.

Greenwood, Robin M., and Annette Vissing-Jorgensen. "The Impact of Pensions and Insurance on Global Yield Curves." SSRN Scholarly Paper. Rochester, NY: Social Science Research Network, December 29, 2018. https://papers.ssrn.com/abstract $=3196068$

Favero, Carlo A., Arie E. Gozluklu, and Haoxi Yang. "Demographics and the Behavior of Interest Rates." IMF Economic Review 64, no. 4 (November 1, 2016): 732-76. https://doi.org/10.1057/s41308-016-0020-2. 
Hall, Robert E. "Understanding the Decline in the Safe Real Interest Rate." Working Paper.

National Bureau of Economic Research, April 2016.

http://www.nber.org/papers/w22196.

Hansen, Bruce E., and Ananth Seshadri. "Uncovering the Relationship between Real Interest Rates and Economic Growth." Working Papers. University of Michigan, Michigan

Retirement Research Center, February 2014.

https://ideas.repec.org/p/mrr/papers/wp303.html.

Joslin, Scott, Kenneth J. Singleton, and Haoxiang Zhu. "A New Perspective on Gaussian Dynamic Term Structure Models." The Review of Financial Studies 24, no. 3 (March 1, 2011): 926-70. https://doi.org/10.1093/rfs/hhq128.

Joslin, Scott, Marcel Priebsch, and Kenneth J. Singleton. "Risk Premiums in Dynamic Term Structure Models with Unspanned Macro Risks." The Journal of Finance 69, no. 3 (2014): 1197-1233. https://doi.org/10.1111/jofi.12131.

Litterman, Robert B., and Josè Scheinkman. "Common Factors Affecting Bond Returns." The Journal of Fixed Income 1, no. 1 (June 30, 1991): 54-61.

https://doi.org/10.3905/jifi.1991.692347.

Ludvigson, Sydney C., and Serena Ng. "Macro Factors in Bond Risk Premia." The Review of Financial Studies 22, no. 12 (December 1, 2009): 5027-67. https://doi.org/10.1093/rfs/hhp081.

McCulloch, J. Huston. "The Tax-Adjusted Yield Curve." The Journal of Finance 30, no. 3 (1975): 811-30. https://doi.org/10.2307/2326860.

Mendoza, Enrique G., Vincenzo Quadrini, Jose-Victor Rios-Rull, "Financial Integration, Financial Development and Global Imbalances," Journal of Political Economy, vo. 117, no. 3 (2009) pp $371-416$.

Mokyr, Joel. 2014. "Ideas, Progress, Wealth, and the Biological Revolution." The Biologist's Imagination: Innovation in the Biosciences, 1. 
Pericoli, Marcello, and Marco Taboga. "Bond Risk Premia, Macroeconomic Fundamentals and the Exchange Rate." International Review of Economics \& Finance 22, no. 1 (April 1, 2012): 42-65. https://doi.org/10.1016/j.iref.2011.08.008.

Summers, Lawrence H. "U.S. Economic Prospects: Secular Stagnation, Hysteresis, and the Zero Lower Bound." Business Economics 49, no. 2 (April 1, 2014): 65-73. https://doi.org/10.1057/be.2014.13.

Vasicek, Oldrich A., and H. Gifford Fong. "Term Structure Modeling Using Exponential Splines." The Journal of Finance 37, no. 2 (1982): 339-48. https://doi.org/10.1111/j.1540-6261.1982.tb03555.x.

Wright, Jonathan H. "Term Premia and Inflation Uncertainty: Empirical Evidence from an International Panel Dataset." American Economic Review 101, no. 4 (June 2011): 1514-34. https://doi.org/10.1257/aer.101.4.1514 